\title{
Sensitivity of seasonal precipitation extremes to model configuration of the Canadian Regional Climate Model over eastern Canada using historical simulations
}

\author{
Philippe Roy • Philippe Gachon • René Laprise
}

Received: 7 August 2013/ Accepted: 21 January 2014/Published online: 1 February 2014

(C) The Author(s) 2014. This article is published with open access at Springerlink.com

\begin{abstract}
This study analyzes the uncertainty of seasonal (winter and summer) precipitation extremes as simulated by a recent version of the Canadian Regional Climate Model (CRCM) using 16 simulations (1961-1990), considering four sources of uncertainty from: (a) the domain size, (b) the driving Atmosphere-Ocean Global Climate Models (AOGCM), (c) the ensemble member for a given AOGCM and (d) the internal variability of the CRCM. These 16 simulations are driven by 2 AOGCMs (i.e. CGCM3, members 4 and 5, and ECHAM5, members 1 and 2), and one set of reanalysis products (i.e. ERA40), using two domain sizes (AMNO, covering all North America and QC, a smaller domain centred over the Province of Québec). In addition to the mean seasonal precipitation, three seasonal indices are used to characterize different types of variability and extremes of precipitation: the number of wet days, the maximum number of consecutive dry days, and the 95th percentile of daily precipitation. Results show that largest source of uncertainty in summer comes from the AOGCM selection and the choice of domain size, followed by the choice of the member for a given AOGCM. In winter, the choice of the member becomes more important than the choice of the domain size. Simulated variance sensitivity is greater in winter than in summer, highlighting the importance of the large-scale circulation from the boundary conditions. The
\end{abstract}

P. Roy $(\bowtie) \cdot$ P. Gachon · R. Laprise

Étude et Simulation du Climat à l'Échelle Régionale (ESCER)

Centre, University of Québec at Montréal, Montreal,

QC H3C 3P8, Canada

e-mail: roy@sca.uqam.ca

P. Gachon

Canadian Centre for Climate Modelling and Analysis, Climate

Research Division, Environment Canada, Montréal,

QC H5A 1L9, Canada study confirms a higher uncertainty in the simulated heavy rainfall than the one in the mean precipitation, with some regions along the Great Lakes-St-Lawrence Valley exhibiting a systematic higher uncertainty value.

Keywords Regional climate modelling - Uncertainty · Extremes · Precipitation · Ensemble · Domain size

\section{Introduction}

There is a growing demand for regional scale information on extreme events used in vulnerability, impacts and adaptation (VIA) studies. The frequency and severity of extreme events and their probable change under climate change play an important role in terms of socioeconomic impacts (Beniston et al. 2007), probably more than changes in the average climate (Mearns et al. 1984; Katz and Brown 1992). One particular concern is the confidence in the simulations of these extreme events: How reliable are they? Are they more uncertain than mean values? A number of studies addressed these issues by evaluating the uncertainty of the mean temperature and precipitation (de Elía and Côté 2010; Déqué et al. 2007; Rowell 2011; Lynn et al. 2009), as well as of extreme events (Kendon et al. 2008; Colin et al. 2010; Mailhot et al. 2012; Wehner 2013), due to model configurations or other considerations (ex. largescale circulation features). Overall, these studies suggest that these uncertainties are significant and should be accounted for when designing ensemble climate projections, and their use in VIA applications.

Atmosphere-Ocean Global Climate Models (AOGCM) are the primary tools used to project climate changes over the entire earth, and generally employ spatial grids of a few hundred of kilometres in horizontal resolution. Such spatial 
resolutions are however insufficient to resolve the physical and dynamical processes that generate precipitation extremes at the regional scale (Wehner et al. 2010) and cannot fulfill regional information demands for most VIA studies and policy makers (Sobolowski and Pavelsky 2012). One way to generate regional information is by using a nested regional climate model (RCM) driven at their lateral atmospheric and surface oceanic boundaries with outputs from an AOGCM or re-analysis. The higher resolution of RCMs can generate more detailed climate simulations at an affordable cost and can take into account regional forcings (orographic features, land/sea coastlines and fine-scale physical and dynamical processes) not explicitly included in AOGCMs (Kendon et al. 2012; Mearns et al. 2003). These RCMs have been demonstrated to provide realistic spatial and temporal detail of regional characteristics of temperature and precipitation at the climatic scale, as well as extremes to some extent (Kjellström and Giorgi 2010; Kendon et al. 2012; Roy et al. 2012). While RCMs represent the state-of-the-art for a consistent simulation of regional scale information, they also add another layer of uncertainty.

Since RCMs use the outputs from AOGCMs as boundary conditions, uncertainties in climate-change simulations combine errors from the AOGCM-RCM cascade and from the downscaling procedure itself and its multiple configurations (domain size, physical parameterization, etc.). Moreover, higher resolution or more complex processes do not equal less uncertainty. For example, new generations of numerical models include significant improvements of complex climate processes and it is believed that they will produce wider ranges of uncertainty in their predictions (Maslin and Austin 2012). For any RCM simulation, a basic configuration includes a choice of an RCM model (or version), a choice of domain size and location, and the choice of a driver (AOGCM or re-analysis) that feeds the nested RCM at its boundary. The sensitivity arising from these choices represents the minimum uncertainty threshold for any given RCM simulation.

By the intrinsic nature of RCMs, the choice of the regional domain remains an arbitrary parameter that governs the solutions (Vannitsem and Chomé 2005). As there are numerous efforts using smaller domain with higher resolution, it is important to assess how much the choice of domain size (DS) affects the simulation of extremes of precipitation. The choice of domain is usually made without a distinction between two different domains, mostly because the spatially averaged values are usually similar (see de Elía and Côté 2010). What VIA groups needs though is regional information at a given limited area pertaining to regional studies, not continental-wide mean values that may not be a faithful representation of local conditions. In that respect, the magnitude of the sensitivity to domain size might prove to spatially fluctuate at the local scale. One popular approach to domain size sensitivity is the Big-Brother experimental set-up (Leduc and Laprise 2009). This approach consists of (1) generating a high-resolution simulation (i.e. the Big Brother), (2) to degrade this simulation with a low-pass filter, (3) to use this degraded simulation to drive smaller domains and (4) to compare the simulations on the common domain. In this set-up, Leduc and Laprise (2009) have shown that the variance of precipitation is significantly affected by a modification of domain size, though these results are based on a perfect-model approach, without consideration to both driving model and driving data deficiencies (Frigon et al. 2010) and based on a limited number (4) of months. Colin et al. (2010) showed that domain size is not detrimental to the modelling of heavy precipitation, highlighting the apparent advantage of using a smaller domain.

Using an ensemble of simulations is a pre-requisite to decipher the signal over the noise, as the uncertainty is related to the spread of multiple realizations (or simulations) and necessitate a certain amount of simulations. The approach of ensemble of simulations consists of combining different AOGCMs with different RCMs so that the ensemble simulations can adequately sample the spread. In that respect, there has been numerous effort in recent years to explore ranges of detailed climate projections by using multi-model ensembles, for example, the Ensemble-Based Predictions of Climate Changes and their Impacts (ENSEMBLES; (Hewitt 2004; van der Linden and Mitchell 2009), Prediction of Regional Scenarios and Uncertainties for Defining European Climate Chang Risks and Effects (PRUDENCE; (Christensen and Christensen 2007), and the North American Regional Climate Change Assessment Program (NARCCAP; (Mearns et al. 2009). However, no in depth analysis of various sources of uncertainties in extreme precipitation values, from available ensemble RCM simulations, have been made over eastern Canada.

The main objective of the present study is to evaluate the sensitivity of seasonal climate extreme indices simulated by the Canadian Regional Climate Model (CRCM, version 4.2.3) to the driving AOGCM, driving AOGCM member, domain size and internal variability. We concentrate on the winter and summer seasons over a region located in northeastern North America. One additional concern is to see if extremes of precipitation are more uncertain than the simulation of mean precipitation. This could have impact on the usual ensemble size that is currently used for mean climate perspective.

The outline is as follows. Section 2 will present the experimental setup, a description of the RCM used for this study, the two domain size, the various sources of boundary conditions used in the RCM simulations, the extreme indices and the performance scores used to quantify the 
Table 1 Acronyms and definitions of the sources of uncertainty

\begin{tabular}{ll}
\hline Acronym & Definition \\
\hline M_RCM & Modification to the starting time of a simulation \\
DS_RCM & Modification of the domain size \\
M_AOGCM & Modification of the AOGCM member \\
C_AOGCM & Modification of the AOGCM
\end{tabular}

uncertainty. In Sect. 3, results are presented, followed by a discussion and conclusion given in Sects. 4 and 5.

\section{Methodology}

\subsection{Experimental setup}

\subsubsection{Model configuration and sources of uncertainties}

This study analyzes the uncertainty of seasonal precipitation extremes as simulated by the version 4.2 .3 of the Canadian RCM (CRCM; Brochu and Laprise 2007; Music and Caya 2007), focusing on four sources of uncertainty (see Table 1): (a) the domain size (DS_RCM), (b) the driving AOGCM (C_AOGCM), (c) the choice of the member for a given AOGCM (M_AOGCM) and (d) the internal variability (M_RCM). The sources of uncertainty are analyzed from daily precipitation from 16 simulations produced at Ouranos (see Tables 2, 3) covering the historical (1961-1990) period. DS_RCM, C_AOGCM and M_AOGCM are estimated with 10 simulations from version 4.2.3 and M_RCM is estimated with 6 simulations using version 4.0.0 and 4.2.0. The simulations are driven by 2 AOGCMs (i.e. CGCM3, members 4 and 5, and ECHAM5, members 1 and 2), and one set of re-analysis product (ERA40, Uppala et al. 2005) from the European Centre for Medium-Range Weather Forecasts (ECMWF) for a total of 5 different drivers. We use 30 years long continuous simulations for summer and 29 years for winter (due to data availability) common to all simulations. Finally, the simulations are spectrally nudged (Biner et al. 2000; von Storch et al. 2000) to ensure that the CRCM follows the large-scale solution of the AOGCMs or reanalysis that drives the CRCM. The use of spectral nudging limits the freedom of the solution inside the simulation domain (compared to a non-nudged simulation), by forcing the large scale features of the RCM towards the large scale solution of the driver. Thus, our experimental setup measures the minimum sensitivity that arises from the basic structural choice associated with any RCM simulation, especially for DS_RCM due to the spectral nudging.

The last source of uncertainty is the internal variability (Laprise et al. 2008; Lucas-Picher et al. 2008). It is the
Table 2 Historical simulations used in the study from the Canadian Regional Climate Model (version 4.2.3)

\begin{tabular}{lll}
\hline Driver & Domain & Simulation \\
\hline CGCM3\#4 & AMNO & aet \\
CGCM3\#5 & QC & afx \\
& AMNO & aev \\
ERA40 & QC & agr \\
& AMNO & ago \\
ECHAM5\#1 & QC & aft \\
& AMNO & agx \\
ECHAM5\#2 & QC & aha \\
& AMNO & ahi \\
& QC & ahu \\
\hline
\end{tabular}

Table 3 Historical simulations used in the study for the assessment of the internal variability, using the Canadian Regional Climate Model (version 4.0.0 and 4.2.0)

\begin{tabular}{|c|c|c|c|c|}
\hline Simulations & $\begin{array}{l}\text { CRCM } \\
\text { version }\end{array}$ & Driver & Domain & $\begin{array}{l}\text { Temporal } \\
\text { window }\end{array}$ \\
\hline$a b t$ & 4.0 .0 & NCEP/NCAR & AMNO & 1959-1999 \\
\hline$a b z$ & 4.0 .0 & NCEP/NCAR & AMNO & $\begin{array}{l}\text { Dec 1st } \\
1958-1999\end{array}$ \\
\hline acw & 4.2 .0 & ERA40 & AMNO & 1958-2002 \\
\hline acx & 4.2 .0 & ERA40 & AMNO & $\begin{array}{l}\text { Dec. 1st } \\
1957-2002\end{array}$ \\
\hline adj & 4.2 .0 & CGCM3\#4 & AMNO & $1958-2000$ \\
\hline aeb & 4.2 .0 & CGCM3\#4 & AMNO & $\begin{array}{l}\text { Dec. 1st } \\
1957-2000\end{array}$ \\
\hline
\end{tabular}

sensitivity of numerical models like RCMs and AOGCMs to the initial conditions used to start simulations and is caused by the chaotic and nonlinear nature of the earth system. It means that two simulations, started from initial conditions close to each other, will present a divergence in terms of instantaneous values over the course of the simulations, resulting in somewhat different climate statistics over a particular time window. This divergence of climate statistics is expected to disappear as the number of years for the averaging increases (de Elía and Côté 2010; Frigon et al. 2010). To ascertain if a given sensitivity is physically significant, the internal variability magnitude is defined as the threshold against which our three other sources of uncertainty (DS_RCM, M_AOGCM and C_AOGCM) are compared (Murphy et al. 2009). To quantify the internal variability, we use 3 experiments (using three different drivers NCEP/NCAR, ERA40 and CGCM3\#4) each consisting of 2 simulations started with one month interval. Since there is a strong influence of the domain size on the magnitude of internal variability (Rinke and Dethloff 2000; 
Table 4 List of the CRCM historical runs used for the sensitivity experiments

\begin{tabular}{|c|c|c|c|}
\hline $\begin{array}{l}\text { CRCM runs (Run } \\
\text { "A"/Run "B") }\end{array}$ & Analysis & Driving data & $\begin{array}{l}\text { Analyzed } \\
\text { period }\end{array}$ \\
\hline $\begin{array}{l}\text { aet/afx }(\mathrm{AMNO} / \\
\mathrm{QC})\end{array}$ & $\begin{array}{l}\text { Domain size } \\
\text { (DS_RCM) }\end{array}$ & CGCM3\#4 & 1961-1990 \\
\hline $\begin{array}{l}\text { aev/agr (AMNO/ } \\
\text { QC) }\end{array}$ & $\begin{array}{l}\text { Domain size } \\
\text { (DS_RCM) }\end{array}$ & CGCM3\#5 & 1961-1990 \\
\hline $\begin{array}{l}\operatorname{agx} / \text { aha }(\mathrm{AMNO} / \\
\mathrm{QC})\end{array}$ & $\begin{array}{l}\text { Domain size } \\
\text { (DS_RCM) }\end{array}$ & ECHAM5\#1 & 1961-1990 \\
\hline $\begin{array}{l}\text { ahi/ahu (AMNO/ } \\
\text { QC) }\end{array}$ & $\begin{array}{l}\text { Domain size } \\
\text { (DS_RCM) }\end{array}$ & ECHAM5\#2 & 1961-1990 \\
\hline $\begin{array}{l}\text { ago/aft }(\mathrm{AMNO} / \\
\mathrm{QC})\end{array}$ & $\begin{array}{l}\text { Domain size } \\
\text { (DS_RCM) }\end{array}$ & ERA40 & 1961-1990 \\
\hline abt/abz (AMNO) & $\begin{array}{l}\text { Internal } \\
\text { variability } \\
\text { (M_RCM) }\end{array}$ & NCEP/NCAR & 1961-1990 \\
\hline acw/acx (AMNO) & $\begin{array}{l}\text { Internal } \\
\text { variability } \\
\text { (M_RCM) }\end{array}$ & ERA40 & 1961-1990 \\
\hline adj/aeb (AMNO) & $\begin{array}{l}\text { Internal } \\
\text { variability } \\
\text { (M_RCM) }\end{array}$ & CGCM3\#4 & 1961-1990 \\
\hline aet/aev (AMNO) & $\begin{array}{l}\text { Member } \\
\text { variability } \\
\text { (M_AOGCM) }\end{array}$ & CGCM3\#4/\#5 & 1961-1990 \\
\hline agx/ahi (AMNO) & $\begin{array}{l}\text { Member } \\
\text { variability } \\
\text { (M_AOGCM) }\end{array}$ & $\begin{array}{l}\text { ECHAM5\#1/ } \\
\quad \# 2\end{array}$ & 1961-1990 \\
\hline afx/agr (QC) & $\begin{array}{l}\text { Member } \\
\text { variability } \\
\text { (M_AOGCM) }\end{array}$ & CGCM3\#4/\#5 & 1961-1990 \\
\hline aha/ahu (QC) & $\begin{array}{l}\text { Member } \\
\text { variability } \\
\text { (M_AOGCM) }\end{array}$ & $\begin{array}{l}\text { ECHAM5\#1/ } \\
\quad \# 2\end{array}$ & 1961-1990 \\
\hline aet/ago (AMNO) & $\begin{array}{l}\text { Driver variability } \\
\text { (C_AOGCM) }\end{array}$ & $\begin{array}{l}\text { CGCM3\#4/ } \\
\text { ERA40 }\end{array}$ & 1961-1990 \\
\hline aet/agx (AMNO) & $\begin{array}{l}\text { Driver variability } \\
\text { (C_AOGCM) }\end{array}$ & $\begin{array}{l}\text { CGCM3\#4/ } \\
\text { ECHAM5\#1 }\end{array}$ & 1961-1990 \\
\hline aet/ahi (AMNO) & $\begin{array}{l}\text { Driver variability } \\
\text { (C_AOGCM) }\end{array}$ & $\begin{array}{l}\text { CGCM3\#4/ } \\
\text { ECHAM5\#2 }\end{array}$ & 1961-1990 \\
\hline aev/ago (AMNO) & $\begin{array}{l}\text { Driver variability } \\
\text { (C_AOGCM) }\end{array}$ & $\begin{array}{l}\text { CGCM3\#5/ } \\
\text { ERA40 }\end{array}$ & 1961-1990 \\
\hline aev/agx (AMNO) & $\begin{array}{l}\text { Driver variability } \\
\text { (C_AOGCM) }\end{array}$ & $\begin{array}{l}\text { CGCM3\#5/ } \\
\text { ECHAM5\#1 }\end{array}$ & 1961-1990 \\
\hline aev/ahi (AMNO) & $\begin{array}{l}\text { Driver variability } \\
\text { (C_AOGCM) }\end{array}$ & $\begin{array}{l}\text { CGCM3\#5/ } \\
\text { ECHAM5\#2 }\end{array}$ & 1961-1990 \\
\hline afx/aft (QC) & $\begin{array}{l}\text { Driver variability } \\
\text { (C_AOGCM) }\end{array}$ & $\begin{array}{l}\text { CGCM3\#4/ } \\
\text { ERA40 }\end{array}$ & 1961-1990 \\
\hline afx/aha (QC) & $\begin{array}{l}\text { Driver variability } \\
\text { (C_AOGCM) }\end{array}$ & $\begin{array}{l}\text { CGCM3\#4/ } \\
\text { ECHAM5\#1 }\end{array}$ & 1961-1990 \\
\hline afx/ahu (QC) & $\begin{array}{l}\text { Driver variability } \\
(\text { C_AOGCM })\end{array}$ & $\begin{array}{l}\text { CGCM3\#4/ } \\
\text { ECHAM5\#2 }\end{array}$ & 1961-1990 \\
\hline agr/aft (QC) & $\begin{array}{l}\text { Driver variability } \\
\text { (C_AOGCM) }\end{array}$ & $\begin{array}{l}\text { CGCM3\#5/ } \\
\text { ERA40 }\end{array}$ & 1961-1990 \\
\hline agr/aha (QC) & $\begin{array}{l}\text { Driver variability } \\
\text { (C_AOGCM) }\end{array}$ & $\begin{array}{l}\text { CGCM3\#5/ } \\
\text { ECHAM5\#1 }\end{array}$ & 1961-1990 \\
\hline
\end{tabular}

Table 4 continued

\begin{tabular}{llll}
\hline $\begin{array}{l}\text { CRCM runs (Run } \\
\text { "A"/Run "B") }\end{array}$ & Analysis & Driving data & $\begin{array}{l}\text { Analyzed } \\
\text { period }\end{array}$ \\
\hline agr/ahu (QC) & $\begin{array}{c}\text { Driver variability } \\
\text { (C_AOGCM) }\end{array}$ & $\begin{array}{c}\text { CGCM3\#5/ } \\
\text { ECHAM5\#2 }\end{array}$ & $1961-1990$ \\
\hline
\end{tabular}

The first column provides the "A"/"B" runs with the respective domain in parenthesis. The second column lists the experiments associated with each pair of simulations given in the first column. The third column provides the driving data and the fourth column gives the time period of the simulations

Lucas-Picher et al. 2008), we only consider the magnitude of internal variability present in the larger domain (AMNO). Note that the spectral nudging has the effect of reducing the internal variability of a RCM (Alexandru et al. 2009).

The evaluation of the sensitivity is done by comparing the differences between two simulations (named run " $\mathrm{A}$ " and run "B"). The 16 simulations are combined to create 24 sensitivity experiments (each experiment being associated with one of the source of uncertainty). Table 4 shows the pair of simulationss used for each experiment. For every experiment, the first and second runs refer respectively to the chosen "A" and "B" runs for each pair. DS_RCM sensitivity is estimated with 5 experiments driven by five different boundary conditions (i.e. comparison between 2 AOGCMs, 2 members of each AOGCM and 1 ERA40 reanalysis driven fields). M_RCM sensitivity is estimated with 3 additional experiments from earlier versions (4.0.0 and 4.2.0) of the CRCM. Those earlier versions had the advantages of having multiple drivers that were used to start simulations at a 1-month interval (see Table 3). M_AOGCM sensitivity is estimated with 4 experiments using the two members of each AOGCM and the two domain sizes. Finally, C_AOGCM sensitivity is estimated with 12 experiments with combination of 2 AOGCMs and 1 reanalysis, 2 members per AOGCM, and the 2 domain sizes. This gives us a total of 24 pair of experiments, or comparisons, using the four tested model configurations.

\subsubsection{The study area}

Figure 1 shows the two domains of integration used in this study and correspond to commonly used grids for CRCM simulations (without the sponge zone). The AMNO grid $(172 \times 180$ grid points) covers North America and a portion of the adjacent oceans and QC grid $(67 \times 91$ grid points) is centred over the Province of Québec with a smaller portion of the North Atlantic Ocean. Results are compared on the common region represented by the QC grid, after removing the 12 most eastern points in the North 


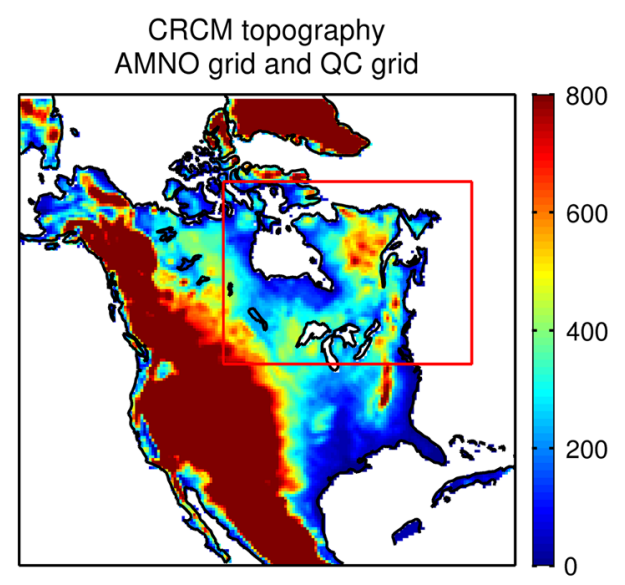

(m)

Fig. 1 AMNO and QC (red box) domains. The topography (in m) is shown in colour scale

Atlantic Ocean. The analysis is done entirely on land-based grid points.

\subsection{Models description}

The RCM model used in this study to produce the 10 simulations associated with three of the four sources of uncertainty (DS_RCM, C_AOGCM and M_AOGCM) (see Table 2) corresponds to the version 4.2.3 of the CRCM (Caya and Laprise 1999; Laprise 2003; Music and Caya 2007). Due to data availability, the 6 other simulations associated with M_RCM sensitivity use version 4.0.0 and 4.2.0 of the CRCM. Both versions (4.0.0 and 4.2.0) use the same physical parameterizations package (Music et al. 2009) and the main difference between them is the addition of the Great Lakes model in the CRCM. The Great Lakes model simulates the evolution of surface temperature and lake ice cover with spatially mixed layer variable depth and is initialized from monthly observations (Goyette et al. 2000). Note that simulations driven with re-analyses do not use the Great Lakes model since observations are used. The addition of the Great Lakes model should not play a major role in the estimation of the internal variability amplitude, as de Elía et al. (2008) has shown that the estimated internal variability from a pair of simulations with greater formulation differences than the addition of the Great Lakes model (modification of soil water capacity and new cloud scheme among other, see Plummer et al. 2006) was rather similar. The CRCM uses the semi-Lagrangian semi-implicit MC2 (compressible community mesoscale model) dynamical kernel (Laprise et al. 1997) with physics parameterization mostly based on the third version of the Canadian AOGCM (CGCM3) (Scinocca and McFarlane 2004).

A mild spectral nudging is applied to horizontal winds and temperature of wavelengths larger than $1,400 \mathrm{~km}$, beginning from zero correction just above $500 \mathrm{hPa}$ and increasing to a maximum strength (a maximum of $5 \%$ of the CRCM large scale are replaced by the driver large scale) at the model top $(\sim 10 \mathrm{hPa})$. All these CRCM versions include the Canadian Land Surface Scheme (CLASS) version 2.7 (Verseghy 2000). CLASS incorporates the exchange of heat and moisture through a sophisticated three-layer soil scheme. For convective parameterisation, all CRCM simulations use the Bechtold-Kain-Fritsch scheme (Bechtold et al. 2001).

The atmospheric and oceanic boundary conditions come from four different sources: (1) ERA40 (Uppala et al. 2005), (2) CGCM3 (members 4 and 5), (3) ECHAM5 (members 1 and 2) and (4) NCEP-NCAR (Kalnay et al. 1996). The update interval of the lateral boundary conditions (LBC) is $6 \mathrm{~h}$. Oceanic data for ECHAM5- and CGCM3-driven simulations comes from the surface oceanic components simulated by the respective coupled AOGCMs, while for ERA40, the oceanic data are prescribed from the Atmospheric Model Intercomparison Project (AMIP) dataset, consisting of monthly sea surface temperature and sea-ice thickness obtained from Fiorino (1997) which are linearly interpolated every day from consecutive monthly values.

The spectral horizontal resolution of CGCM3 is T47 $\left(\sim 2.8^{\circ} \times 2.8^{\circ}\right)$ and T63 for ECHAM5 $\left(\sim 1.9^{\circ} \times 1.9^{\circ}\right)$. Both AOGCM have 31 vertical levels with the top layer of CGCM3 at $1 \mathrm{hPa}$ and ECHAM5 at $10 \mathrm{hPa}$. A complete description of CGCM3 and ECHAM5 models is available in Scinocca et al. (2008) and Roeckner et al. (2003), respectively.

\subsection{Analysis}

This section describes the extreme indices used to characterize the magnitude and frequency of seasonal extreme events and the performance scores used to quantify the sensitivity.

\subsubsection{Extreme indices definitions}

In addition to the mean seasonal precipitation (Precip, in $\mathrm{mm} /$ day), three seasonal extreme indices are used to characterize different types of variability and extremes of precipitation (see Table 5): the wet-days frequency, Prcp1 (\%), using a threshold of $1 \mathrm{~mm} /$ day (see Hennessy et al. 1999); the 95th percentile of daily precipitation, P95 (mm/ day), also using the $1 \mathrm{~mm} /$ day threshold (hence, P95 is the 95th percentile of wet days seasonal sample); and the maximum number of consecutive dry days, CDD (days), with the same $1 \mathrm{~mm} /$ day threshold. These extreme indices are calculated at each grid point, at the seasonal scale for winter (DJF) and summer (JJA), for each year and for each 
Table 5 List of the three extreme indices used in the study to analyze wet days, maximum duration of dry sequences and heavy rainfall

\begin{tabular}{lll}
\hline Name & Description (unit) & Type \\
\hline Precip & Mean precipitation & Intensity \\
Prcp1 & Days with precipitation $\geq 1 \mathrm{~mm}$ (days) & Frequency \\
CDD & $\begin{array}{c}\text { Maximum number of consecutive dry days } \\
\text { (days) }\end{array}$ & Duration \\
P95 & 95th percentile of daily precipitation (mm/day) & Intensity
\end{tabular}

For more details, please refer to STARDEX, and to ETCCDI (Expert Team on Climate Change Detection and Indices, see http://www. clivar.org/organization/etccdi/etccdi.php)

simulation using the 30-years period (1961-1990) information.

\subsubsection{Performance score}

\subsubsection{Simulated variance ratio and spatial correla-} tion Synthetic diagrams showing the spatially averaged temporal variance ratio (VR, see Roy et al. 2012) and the spatial correlation (SC) of 30-year climatology are used to inform us on important aspects of both temporal and spatial characteristics of the simulated extreme indices. VR indicate whether or not a given source of uncertainty has an impact on the amplitude and frequency of extreme events.

VR is defined as the ratio of the run "B" temporal interannual variance divided by run " $\mathrm{A}$ " temporal interannual variance, and then spatially averaged over all land grid points.

$V R_{m}=\frac{1}{G P} \sum_{i=1}^{G P} \frac{\sigma_{B_{i m}}^{2}}{\sigma_{A_{\text {im }}}^{2}}$

where $\sigma_{B_{\text {im }}}^{2}$ and $\sigma_{A_{\text {im }}}^{2}$ are the simulations "B" and "A" respectively. GP is the total number of land grid points and $m$ refer to a given experiment (listed in Table 4).

SC is defined as the Spearman's correlation of the 30-year climatological spatial pattern between simulations "A" and "B". The Spearman correlation test is a nonparametric ranked correlation coefficient. The advantage of using a ranked test like Spearman's is the robustness to outliers.

2.3.2.2 Ensemble absolute mean sensitivity The ensemble absolute mean sensitivity (EAMS) measures the climatology sensitivity to a given source of uncertainty and informs us on the interaction between the sources of uncertainty and the regional climate processes. The absolute climatological sensitivity for a given grid point, defined as the time-mean differences $(\Delta \mathrm{E})$ for seasonal mean precipitation or seasonal extreme indices of precipitation for experiment $m$ (see Table 4), is given by:
$\Delta \overline{E_{m}}=\frac{1}{N} \sum_{j=1}^{N}\left|E_{B_{j m}}-E_{A_{j m}}\right|$

where $E_{B_{j m}}$ and $E_{A_{j m}}$ is the seasonal grid-point value of the " $\mathrm{B}$ " simulation and the "A" simulation, respectively, for year $\mathrm{j}=1, \ldots, \mathrm{N}$ for experiment $m$. The EAMS is defined as the average of Eq. 2 over either all experiments or the sub-ensemble for each source of uncertainty. Hence, the EAMS of DS_RCM is computed by using the 5 experiments associated with DS_RCM and so on for the other source.

The relative climatological absolute sensitivity for a given grid point is given by:

$R \_\Delta \overline{E_{m}}=\frac{1}{N} \sum_{j=1}^{N}\left(\left|\frac{E_{B_{j m}}-E_{A_{j m}}}{E_{A_{j m}}}\right|\right) x 100$

The R_EAMS is defined as the average of Eq. 3 over all experiments. Again, the "ensemble" refers either to the whole 24 experiments or to the sub-ensemble for each source of uncertainty. When the absolute operator is not used, we refer to the ensemble mean sensitivity (EMS) and the relative ensemble mean sensitivity (R_EMS).

For each experiment $m$, an unpaired Student's $t$ test is applied to test for the equality of the means of the "A" and "B" 30-year distributions values at each grid point and only the statistically significant grid-point differences are kept.

2.3.2.3 Variance decomposition of the sensitivity The total uncertainty is defined as the response of a given extreme index to model configuration and is estimated using the variance estimator:

$\hat{\sigma}_{T O T}^{2}=\frac{1}{M-1} \sum_{m=1}^{M}\left(\Delta \overline{E_{m}}-\left\langle\Delta \overline{E_{m}}\right\rangle\right)^{2}$

where $\mathrm{M}$ is the number of experiments (24) in the ensemble, $\hat{\sigma}_{T O T}^{2}$ denotes an unbiased variance estimator of $\Delta \overline{E_{m}}$ and $\left\langle\Delta \overline{E_{m}}\right\rangle$ denotes the ensemble mean of $\Delta \overline{E_{m}}$. It can be shown that Eq. 4 can be decomposed into four components:

$\hat{\sigma}_{T O T}^{2}=\hat{\sigma}_{M \_R C M}^{2}+\hat{\sigma}_{D S \_R C M}^{2}+\hat{\sigma}_{M \_A O G C M}^{2}+\hat{\sigma}_{C \_A O G C M}^{2}$

All of these four components are estimated with a discrimination of our ensemble based on our model configurations. Once the variances are estimated, we compute the ratio (relative variance contribution) of each configuration to the total uncertainty. Hence, we get the following ratio relations $\left(\mathrm{R}_{\mathrm{s}}\right)$ : 
$R_{M \_R C M}=\frac{\hat{\sigma}_{M \_R C M}^{2}}{\hat{\sigma}_{T O T}^{2}}$

$R_{D S \_R C M}=\frac{\hat{\sigma}_{D S \_R C M}^{2}}{\hat{\sigma}_{T O T}^{2}}$

$R_{M \_A O G C M}=\frac{\hat{\sigma}_{M \_A O G C M}^{2}}{\hat{\sigma}_{T O T}^{2}}$

$R_{C \_A O G C M}=\frac{\hat{\sigma}_{C \_A O G C M}^{2}}{\hat{\sigma}_{T O T}^{2}}$

\subsubsection{Sample size impact on estimation (i.e. sampling error)}

As evidenced by Table 4, the number of experiments for a given source of uncertainty is not constant. The impact of sample size in the estimation of the performance scores (EAMS and $\hat{\sigma}_{T O T}^{2}$ ) is briefly evaluated. For a given number of experiments (see Table 4) $n$, the procedure is as follow:

1. Randomly pick $n$ experiments among the 24 available from Table 4 and calculate the value of EAMS and $\hat{\sigma}_{T O T}^{2}$ for 10 grid points (randomly located over the common QC region. The same 10 grid points are kept for the whole bootstrapping procedure) and take the average of the 10 grid points.

2. Repeat step one 3,000 times.

3. Estimate the mean and standard deviation of these 3,000 estimations of EAMS and $\hat{\sigma}_{T O T}^{2}$ and calculate the coefficient of variation.

4. Repeat step 1-3 for another value of $n$, where $n$ vary from 3 to 24 .

Figure 2 shows the $\mathrm{CV}$ values for both EAMS and $\hat{\sigma}_{T O T}^{2}$. It is important to mention that we use a random subset of the whole 24 sensitivity experiment ensemble (constructed with the 16 simulations, see Table 4) in these calculations. This means that the line indicating the ensemble size for M_RCM $(\mathrm{n}=3)$, M_AOGCM $(\mathrm{n}=4), \mathrm{DS} \_R C M(\mathrm{n}=5)$ and C_AOGCM $(\mathrm{n}=12)$ is shown only as an informative view, not as the real uncertainty attributed to any given source. As shown in Fig. 2, the CV values for both EAMS and $\hat{\sigma}_{T O T}^{2}$ are inversely proportional to the square of the sample size $n$. For EAMS (Fig. 2a), Precip and P95 show a higher variability with respect to their mean values than CDD and Prcp1, for any given ensemble size. Roughly speaking for Precip, the sampling uncertainty of EAMS with respect to available numbers of samples per source of uncertainty, results for EAMS are $45 \%$ more uncertain (in terms of their relative CV values) for DS_RCM (with 5 combinations), $67 \%$ for M_AOGCM (with 4 combinations) and $88 \%$ for M_RCM (with 3 combinations), when compared to C_AOGCM (with 12 combinations). The other indices follow a similar pattern, with decreasing $\mathrm{CV}$ values with increasing available member.

For $\hat{\sigma}_{T O T}^{2}$, the spread of CVs between indices for a given $n$ is higher than for EAMS. This is expected since $\hat{\sigma}_{T O T}^{2}$ is derived from the estimation of EAMS and the error propagates from it. Frequency-and duration-based indices (Prcp1 and CDD, respectively) have lower CV values, suggesting a lower spread of these indices. The inter-season difference is significant for Prcp1 only, with a higher value in summer. Roughly speaking for Precip, the sampling uncertainty of $\hat{\sigma}_{T O T}^{2}$ with respect to available numbers of samples per source of uncertainty, results for $\hat{\sigma}_{T O T}^{2}$ are $76 \%$ more uncertain for DS_RCM, $96 \%$ for M_AOGCM and $128 \%$ for M_RCM, when compared to C_AOGCM. We note that the inter-indices decreasing rate of estimation uncertainty is more variable than for EAMS and hence, these relative sampling uncertainty numbers (calculated from the Precip indices) are mostly for quick reference and shed some light on the robustness of each sources of uncertainty in terms of sample size.

Hence, this brief relative uncertainties analysis stresses the importance of having a comprehensive ensemble size to reduce the errors due to the sample size. Obviously, the results are more robust for C_AOGCM, then for the 3 other source of uncertainty.

\section{Results}

\subsection{Variance ratio and spatial correlation sensitivities}

Figure 3 shows the synthetic diagrams showing the SC of 30 -years climatology and the spatially averaged temporal VR of the four sources of uncertainty for all the experiments defined in Table 4. As shown in Table 4, the "A" simulations for DS_RCM sensitivity is based on the AMNO grid reference. Hence, VR values higher than 1 mean that the QC grid simulated values produces higher interannual variance with respect to the AMNO grid ones. On the other hand, for C_AOGCM M_AOGCM and M_RCM sensitivities, the "A" and "B" runs are an arbitrary choice. However, we see that for C_AOGCM, simulations "A" are always associated with CGCM3 (both members) and simulations "B" are either associated with ERA40 or ECHAM5 (both members). This means that VR values over 1 for C_AOGCM indicate higher variability from the LBC from ERA40 and ECHAM5. As explained in Sect. 2.1, the range of M_RCM (i.e. maximum and minimum values for VR and SC) can be seen as the significant threshold and the range of values against which other results are compared. 
(a) Ensemble mean estimation sensitivity to sample size

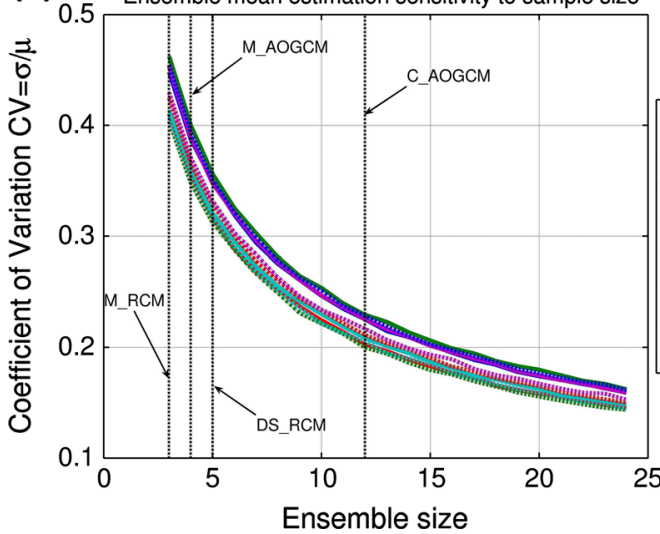

(b)

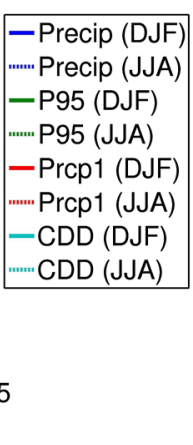

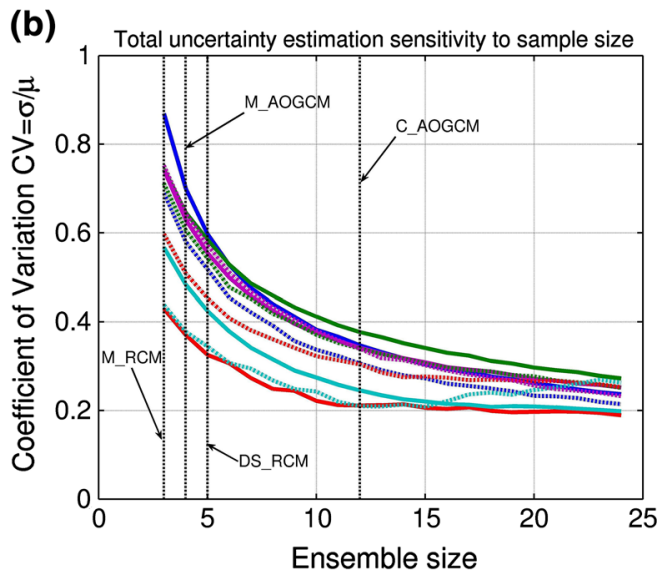

Fig. 2 Coefficient of variation (CV) of mean seasonal precipitation and precipitation indices for DJF and JJA, for ensemble absolute mean sensitivity (EAMS, left panel) and total uncertainty $\left(\hat{\sigma}_{T O T}^{2}\right.$, right panel $)$ estimations versus ensemble size
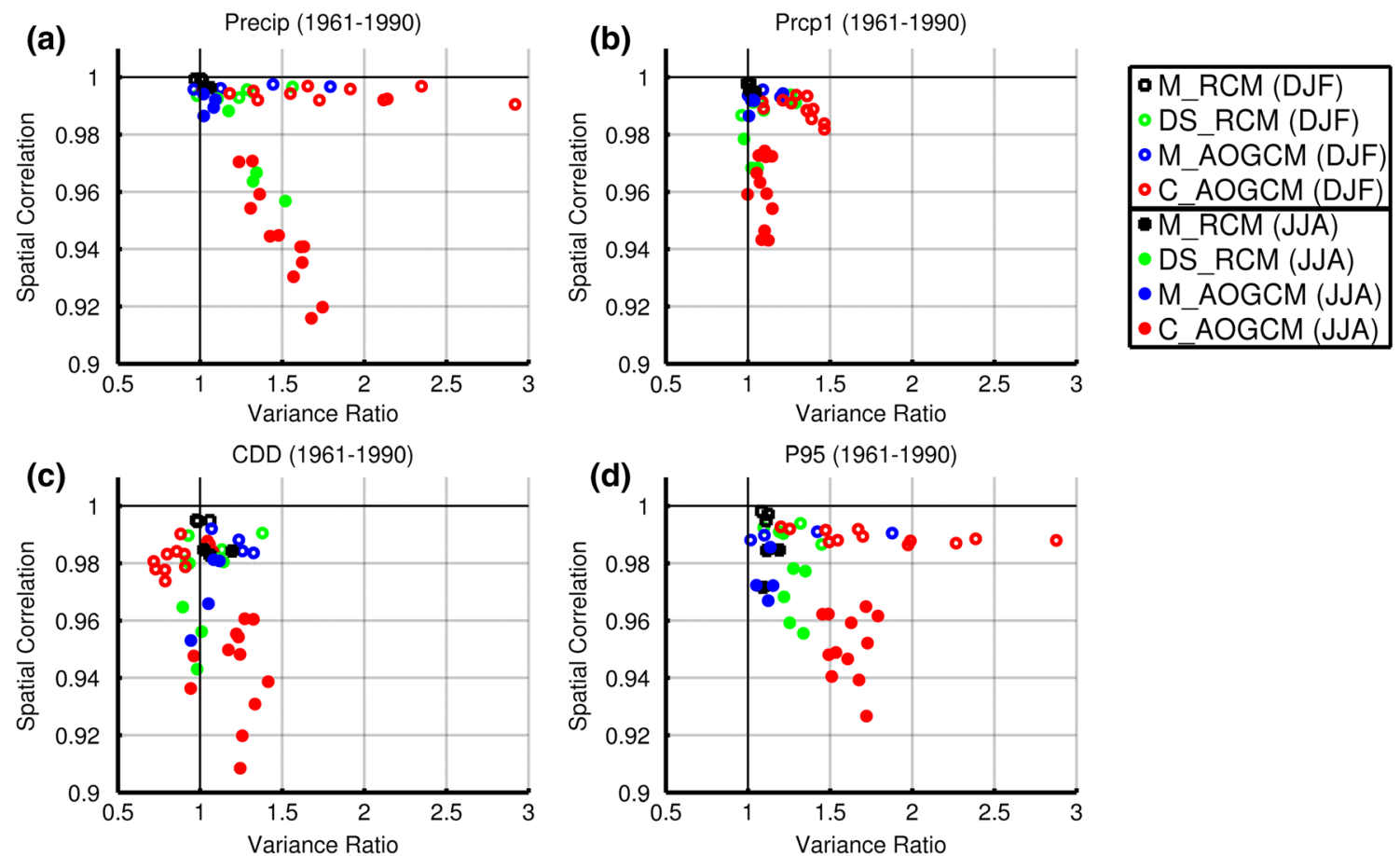

Fig. 3 Spatial correlation (SC) versus variance ratio (VR) for all experiments defined in Table 4. Cyan color is for the internal variability (M_RCM), green color is for the choice of domain (DS_RCM), blue color is for the choice of AOGCM member

(M_AOGCM) and red color is for the choice of LBC (C_AOGCM). Open marker represent winter (DJF) season while a filled marker represent summer (JJA) season

\subsubsection{Variance ratio}

Interannual variability (i.e. VR) of Precip and P95 is largely influenced by lateral boundary conditions (i.e. C_AOGCM and M_AOGCM), especially in DJF with VR value as high as 3 for C_AOGCM and 1.75 for M_AOGCM. For DS_RCM, the sensitivity of VR is slightly lower than M_AOGCM for Precip and P95 (ranging from 1 to 1.5 ) but higher than M_AOGCM for

Prcp1 and CDD. The sensitivity of the winter interannual variability is lower for frequency-based indices (i.e. Prcp1 and CDD), compared to intensity indices, with VR values ranging from 0.75 to 1.5 . DS_RCM, M_AOGCM and C_AOGM are all significant compared to the internal variability of the CRCM (M_RCM).

In summer, the sensitivity of the interannual variability is lower than in winter, with values ranging from 0.9 (CDD, Fig. 3c) to 1.75 (Precip, Fig. 3a and P95, Fig. 3d). 
For Prcp1, the sensitivity of VR is low in summer relative to DJF. It is noteworthy to see that the sensitivity of VR for DS_RCM for Precip and P95 is similar in winter (VR ranging from 1 to 1.5 ) and summer (VR ranging from 1.1 to 1.5). Only DS_RCM (Precip and P95) and C_AOGCM (all indices) are significant compared to M_RCM.

\subsubsection{Spatial correlation}

SC variations are much less important, especially in winter with SC values between 0.98 and 0.99 , which are within the range of the internal variability (i.e. M_RCM). In summer, the degradation of the SC is more important, with values ranging from 0.91 to 0.99 , which is higher than M_RCM, with the exceptions of summer M_AOGCM P95 that is similar to M_RCM (Fig. 3d).

\subsubsection{Summary of variance ratio and spatial correlation results}

The higher range of VR in winter highlights the importance of the synoptic flow variability (caused by modifying the LBC driver or data at the lateral boundary) for the sensitivity of the interannual variability. This is expected since the variance of most atmospheric fields is typically contained within the largest scales (Laprise 2003), so it's no surprise that the VR is higher in winter than in summer, where the large-scale synoptic forcing is predominant with a strong circulation. Even though the range of possible VR is higher in winter than summer, SC values are higher in winter. This indicates that fine-scale processes play an important role for regional characteristics of precipitation and extreme indices in summer, and differences in summer will be enhanced by these finescale features. Finally, C_AOGCM and M_AOGCM values are limited to values higher than one (with the exceptions of CDD in winter). This is probably caused $\mathrm{b}$ a higher variability in the large scales field at the LBC (horizontal wind fields, water vapor, temperature and pressure) from the driver associated with simulations " $B$ " (i.e. ERA40 and ECHAM5). It is not clear why M_AOGCM has such a high sensitivity, since different member from the same driving model should lead to similar LBC. However, VR measures the sensitivity at the interannual timescale and at such temporal scales (and with only 30 years averages) the internal atmospheric variability is important (Deser et al. 2012).

With the exception of CDD (all seasons) and Prcp1 (summer and spring), using the QC grid produces higher variance, relative to the AMNO grid, as evidenced by DS_RCM VR values close (Prcp1 and CDD) or higher (Precip and P95) than one. This is true for all four seasons (not shown for spring and autumn).

\subsection{Maps}

We now look at the spatial distribution of the 30-year climatological EAMS (Sect. 2.3.2) and the relative contributions to the total variance ("R", Sect. 2.3.2) associated with three of the four sources (DS_RCM, C_AOGCM and M_AOGCM) of uncertainty for mean precipitation and extreme indices. Results for the internal variability (M_RCM) is not shown (for brevity) in this section as M_RCM EAMS is not statistically significant over most of the common region of analysis and represents only $10 \%$ of the contribution to the total uncertainty within our ensemble.

\subsubsection{EAMS spatial patterns}

3.2.1.1 Sensitivity of EAMS to domain size The left panels of Figs. 4 and 5 show the EAMS due to the domain size for DJF and JJA, respectively. A distinctive zone (south eastern part of the domain) of higher EAMS values is present for both seasons, with a clear regional variation among the land areas along the south-eastern and eastern regions where the major tracks of synoptic extra-tropical cyclones are located. A modification of the domain size results in different atmospheric conditions and surface conditions along the Atlantic Coast (among other places), while keeping the oceanic conditions identical (i.e. prescribed by the same AOGCM for both simulations associated with DS_RCM experiments). This difference (between 2 simulations) will cause variability (between DS_RCM experiments) in the baroclinicity along the Atlantic Coast (where most intense North American midlatitude storms tend to track) and hence modify the storm track.

In DJF, the main effects of the domain size are located south of the St-Lawrence Valley [Precip $(\sim 1 \mathrm{~mm})$, P95 $(\sim 7 \mathrm{~mm})$ and Prcp1 $(\sim 3 \%)$ ], the Appalachian Mountains [Precip $(\sim 1.5 \mathrm{~mm})$, P95 $(\sim 9 \mathrm{~mm})$ and Prcp1 $(\sim 3 \%)$ ] and Newfoundland [P95 $(\sim 8 \mathrm{~mm})$ ], i.e. along the water masses and high or discontinuous orographic features.

In JJA, the main areas of sensitivity are located southeast of the Great Lakes [Precip $(\sim 2.5 \mathrm{~mm})$, Prcp1 ( $\sim 5 \%)$, P95 ( $\sim 15 \mathrm{~mm})$ and CDD ( $\sim 2$ days)], consistent with a strong north-south gradient of summer climatological precipitation values (not shown). There is also a significant sensitivity over the south-western part of the domain, mainly for wet days and dry sequences [Prcp1 ( $\sim 5 \%)$ and CDD ( $\sim 2$ days) $)$, where we expect a significant number of convective storms.

Figure 6 shows the ensemble mean relative sensitivity (Eq. 3, without the absolute operator) associated with DS_RCM for Precip and the extremes indices. In both winter and summer seasons, on average, the QC domain 
DJF

(a)

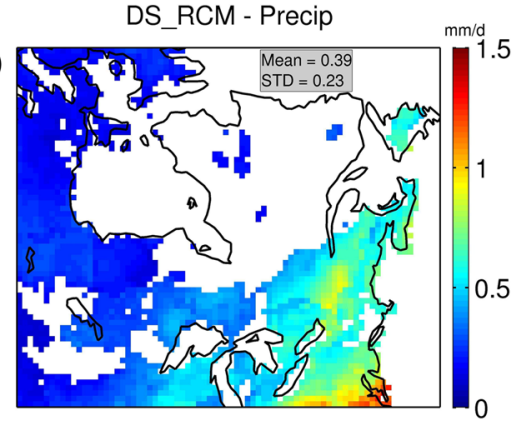

(d)

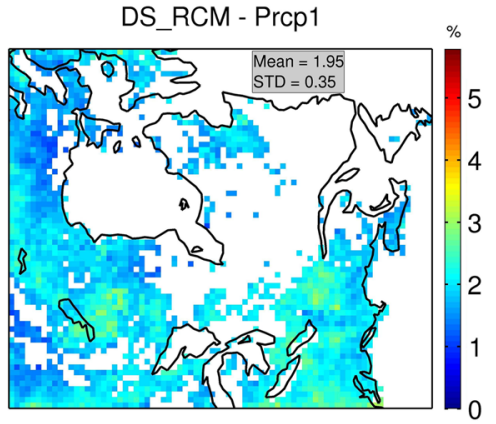

(g)

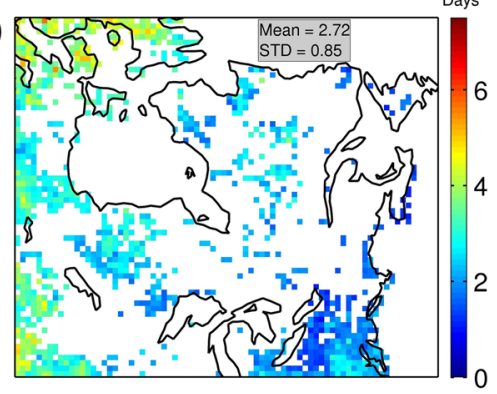

(j)

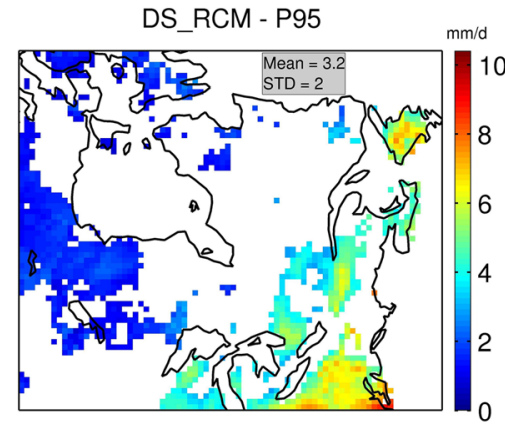

(b)

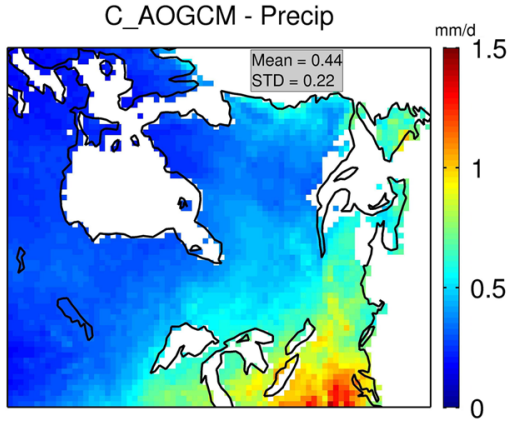

C_AOGCM - Prcp1

(e)

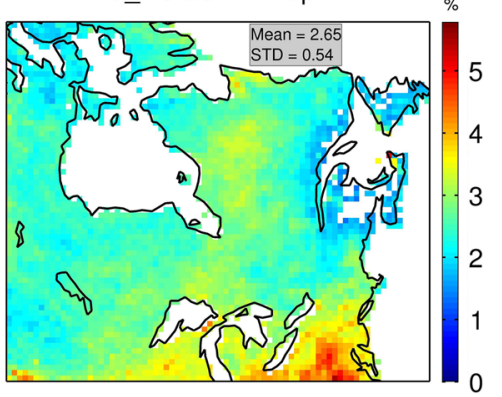

(h)

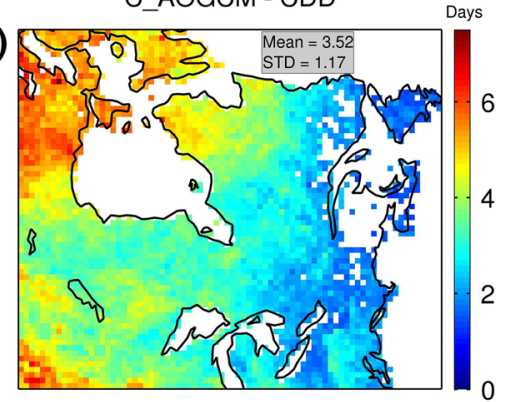

C AOGCM - P95

(k)

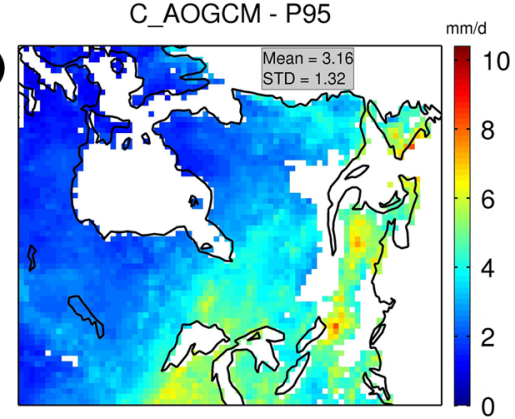

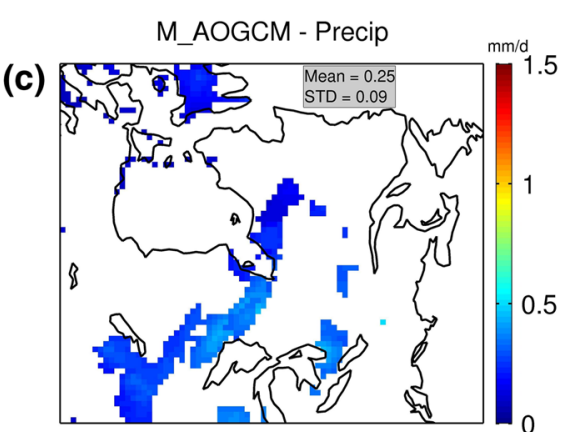

(f)

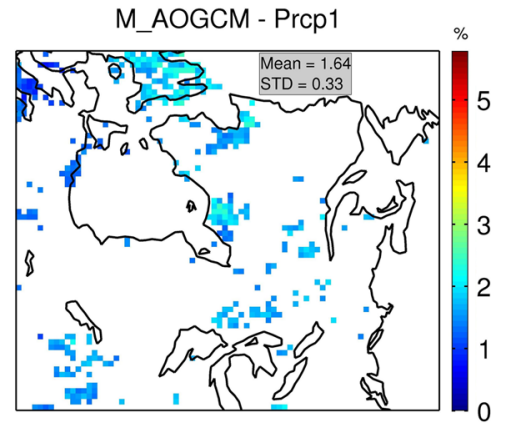

(i)
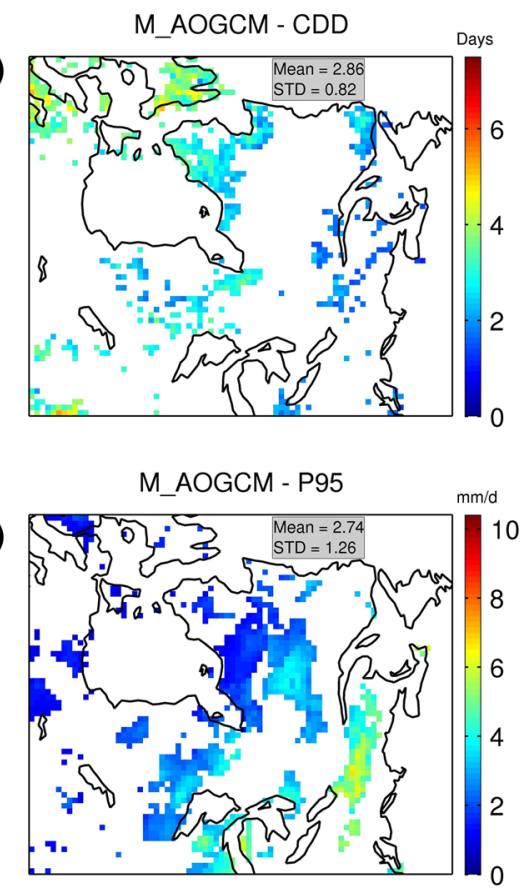

Fig. 4 Winter (DJF) ensemble absolute mean sensitivity of DS_RCM (left panels), C_AOGCM (middle panels) and M_AOGCM (right panels) for Precip (a-c), Prcp1 (d-f), CDD (g-i) and P95 (j-l). Only the statistically significant values at the $95 \%$ level (using the Student's $t$ test) are shown in colour scale

seasonal behaviour in the sign or range of differences, except for the occurrence of wet days where two times higher values are obtained in winter than in summer. The higher values of precipitation and wet days amount within the QC grid (with respect to AMNO grid) correspond to 
JJA

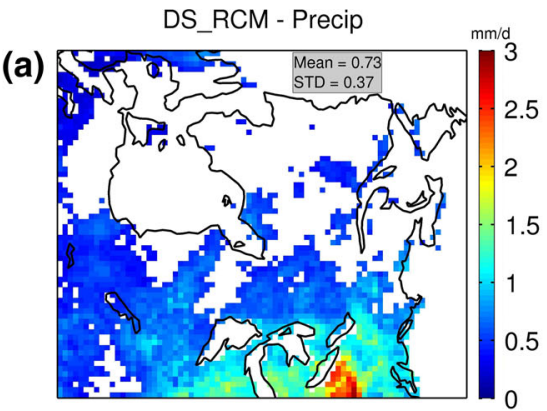

(d)
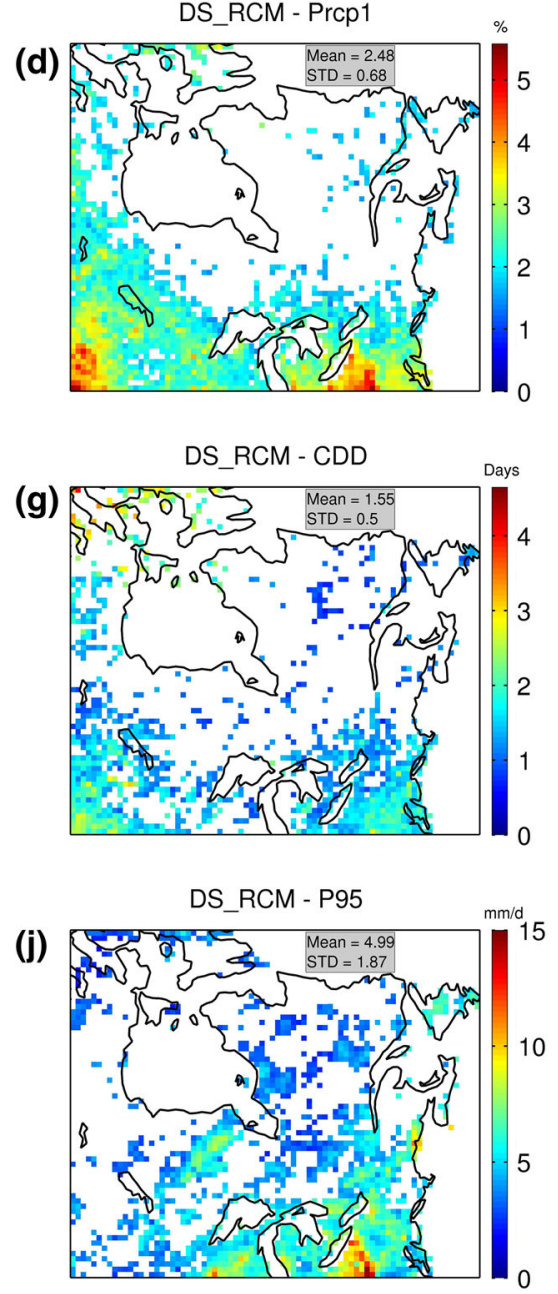

Fig. 5 Summer (JJA) ensemble absolute mean sensitivity of DS_RCM (left panels), C_AOGCM (middle panels) and M_AOGCM (right panels) for Precip (a-c), Prcp1 (d-f), CDD (g-i) and P95 (j-l).

fewer dry sequences (CDD) or more intense precipitation events in general (i.e. P95, see Fig. 6, panels e to h).

\subsubsection{Sensitivity of EAMS to driving data (AOGCMs} and/or ERA40 reanalyses) The middle panels of Figs. 4 and 5 present the EAMS due to the modification of the driving data (C_AOGCM) for DJF and JJA, respectively. (b)

(e)

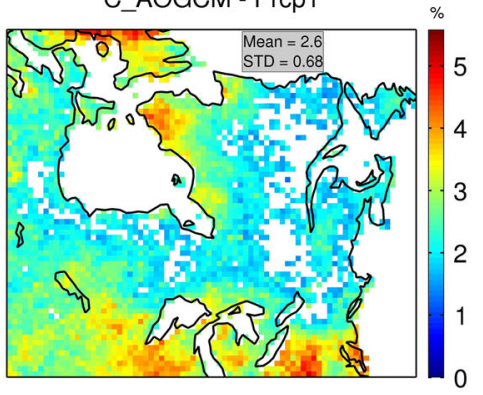

C_AOGCM - CDD

h)

(k)

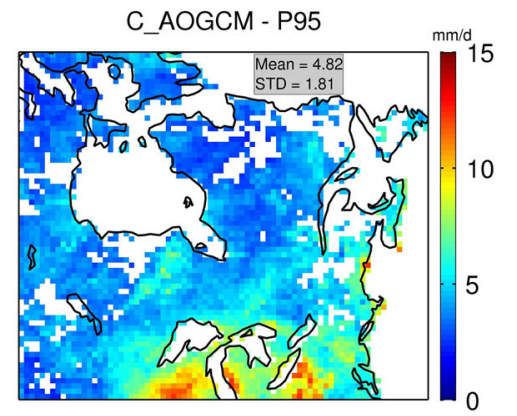

(c)

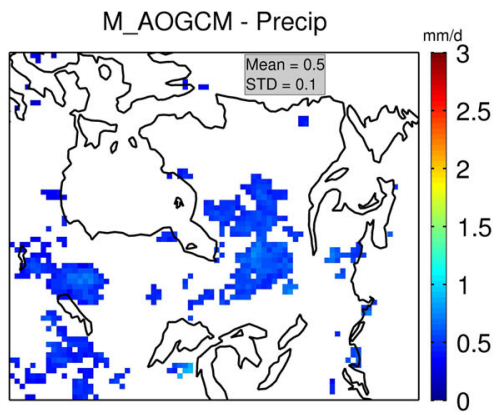

(f)

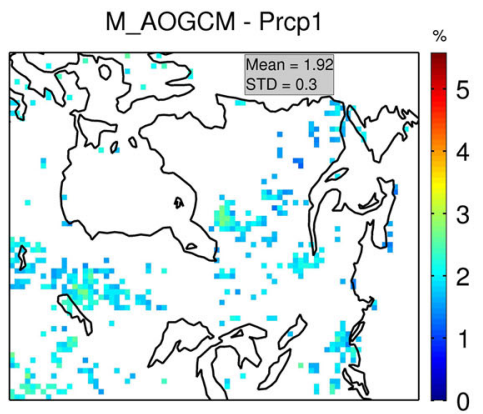

(I)

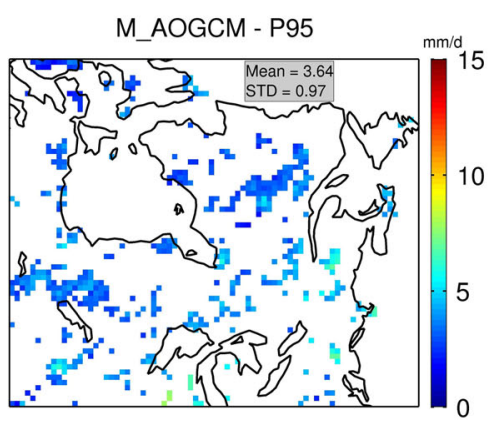

Only the statistically significant values at the $95 \%$ level (using the Student's $t$ test) are shown in colour scale

The choice of AOGCM (including reanalyses) LBC is the main contributor for the inter-model simulation variability, following mainly by the DS_RCM sensitivity and in a lesser extent by M_AOGCM experiments. The C_AOGCM effect is widespread over most of the common region (QC grid) with a statistically significant pattern for all variables of precipitation. Depending on the seasons and the 
Fig. 6 R_EMS associated with DS_RCM for Precip, Prcp1, CDD and P95 for DJF (left panels) and JJA (right panels) (a)

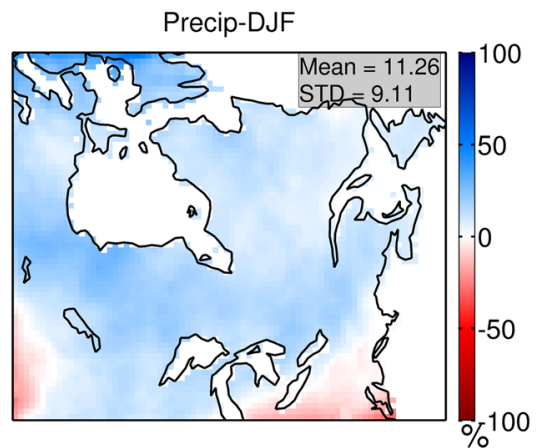

(c)

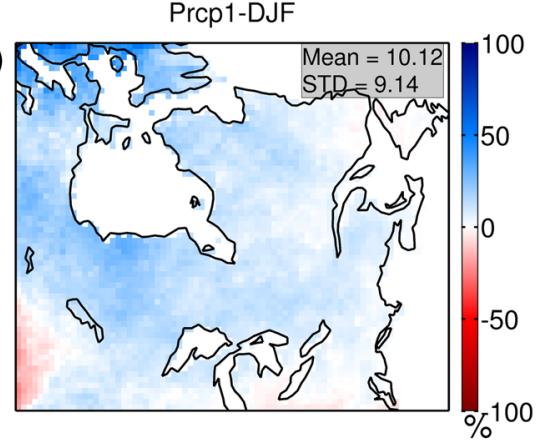

(e)
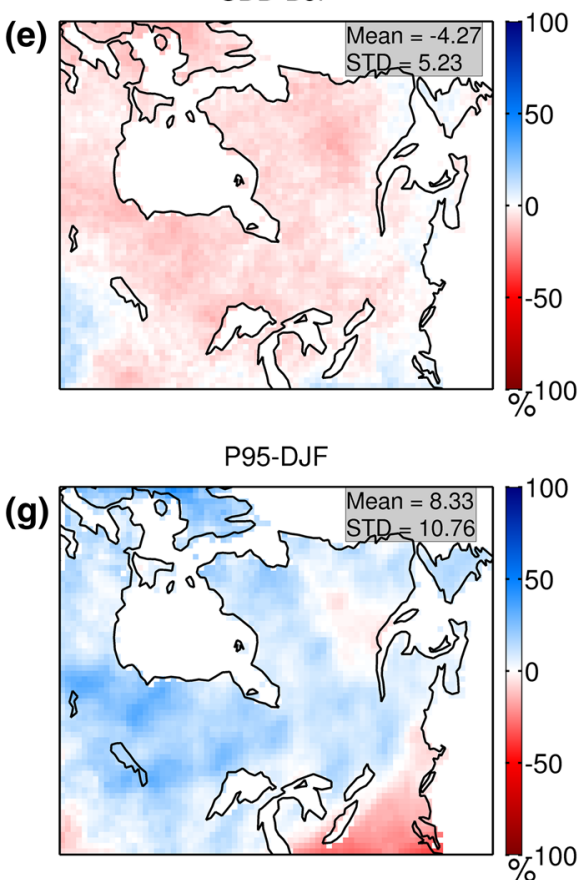
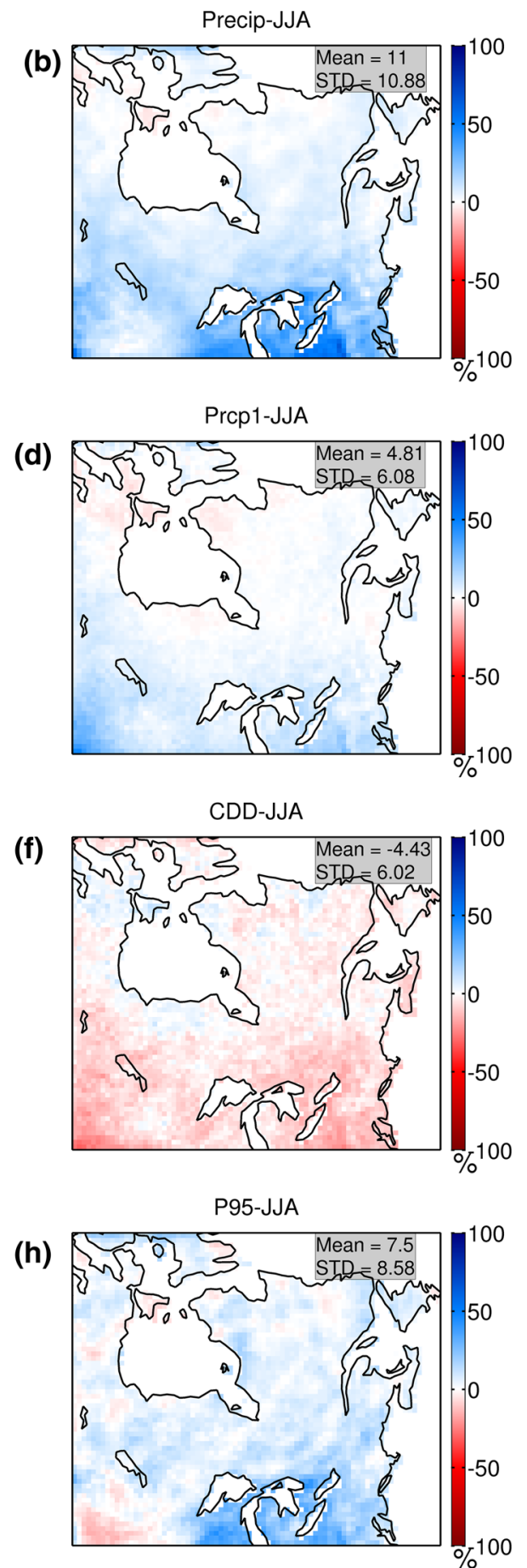

Table 6 Spatially averaged R_EMS associated with DS_RCM

\begin{tabular}{lcl}
\hline & DJF $(\%)$ & JJA $(\%)$ \\
\hline Precipitation & 11.26 & 11 \\
Prcp1 & 10.12 & 4.81 \\
CDD & -4.27 & -4.43 \\
P95 & 8.33 & 7.5 \\
\hline
\end{tabular}

considered indices, higher sensitivity patterns seem to emerge near land-sea contrasts or mountainous regions around the Hudson Bay, the Great Lakes and the Appalachian Mountains, as noted before in the DS_RCM combinations but in the case of C_AOGCM with exacerbating influences (for example, different SSTs between two driving models). 


\section{$R_{\text {DS_RCM }}$ - Precip}

(a)

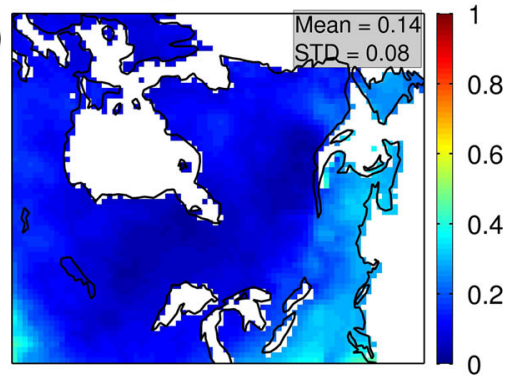

$\mathrm{R}_{\mathrm{DS} \_ \text {RCM }}-\operatorname{PrCp} 1$

(d)

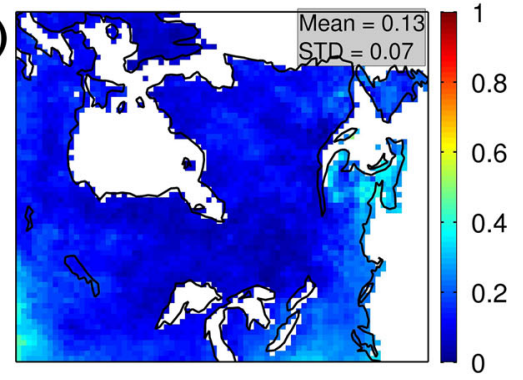

$R_{D S \_R C M}-C D D$

(g)

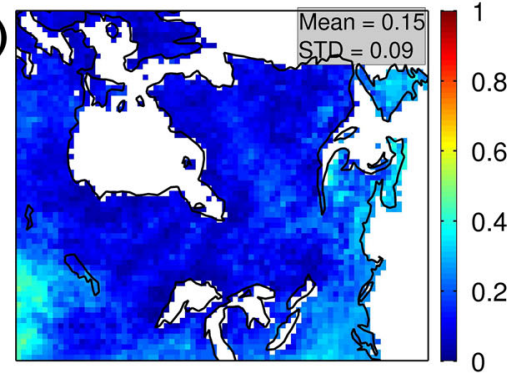

$R_{D S \_R C M}-P 95$

(j)

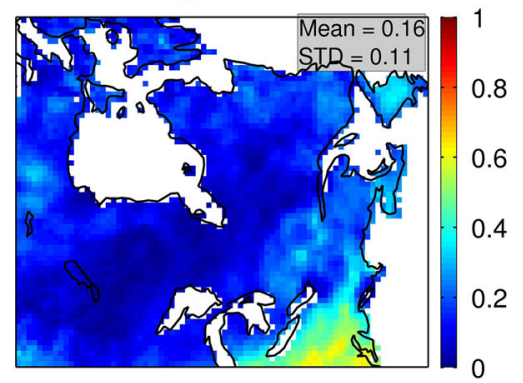

\section{DJF}

$R_{\mathrm{C}_{\text {AOGGCM }} \text { - Precip }}$

(b)

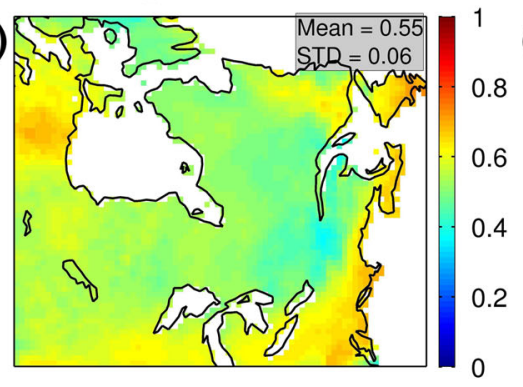

$R_{\text {C_AOGCM }}$ - Prcp1

(e)

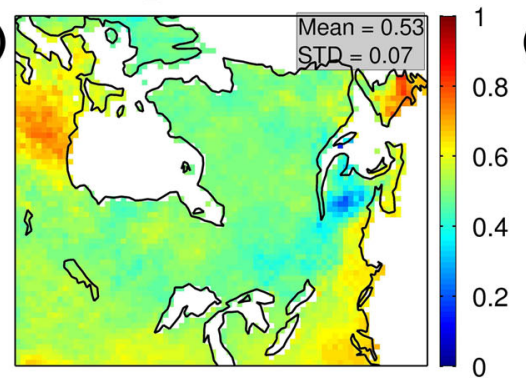

$R_{\text {C_AOGCM }}-$ CDD

(h)

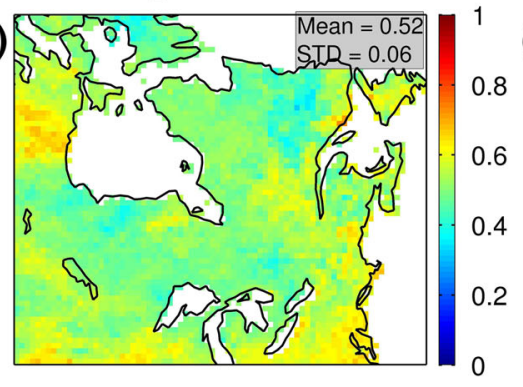

$\mathrm{R}_{\mathrm{C} \text { AOGCM }}$ - P95

(k)

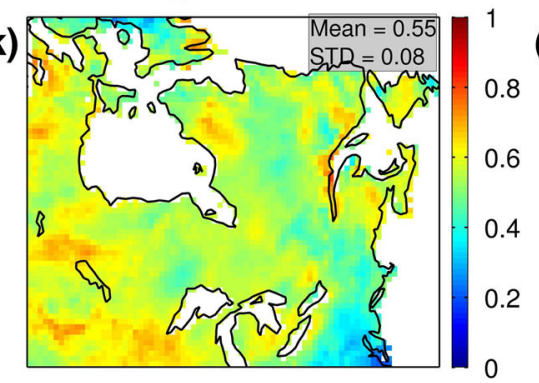

(c)

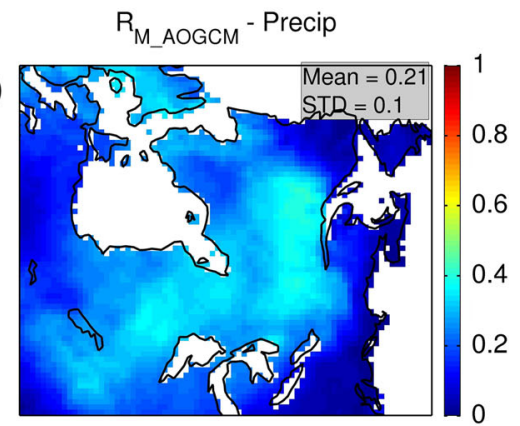

(f)

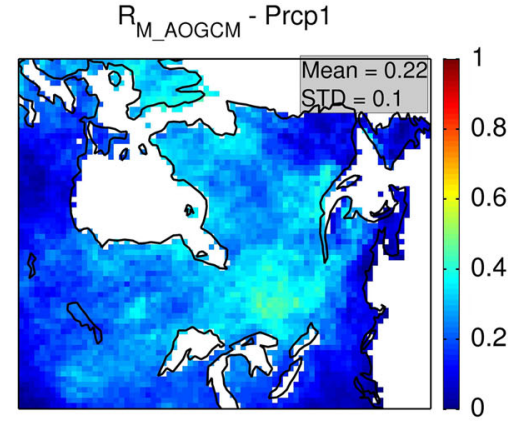

(i)

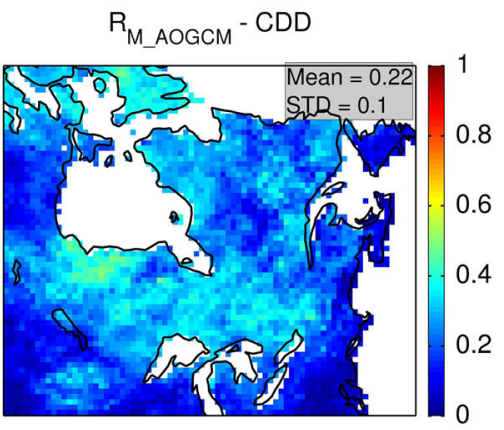

(I)

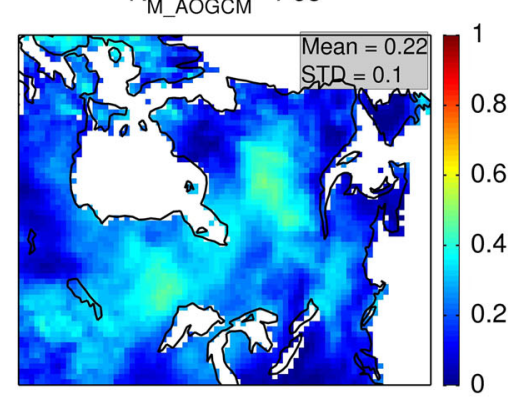

Fig. 7 Winter (DJF) relative contribution to the total uncertainty (R) of DS_RCM (left panels), C_AOGCM (middle panels) and M_AOGCM (right panels) for Precip $(\mathbf{a}-\mathbf{c})$, Prcp1 $(\mathbf{d}-\mathbf{f}), \operatorname{CDD}(\mathbf{g}-\mathbf{i})$ and P95 (j-l)

For DJF, the areas of high sensitivity are located over the Appalachian Mountains [P95 ( $~ 8 \mathrm{~mm})$ ] and south of the Great Lakes [Precip $(\sim 1.5 \mathrm{~mm})$ and Prcp1 $(\sim 5 \%)$ ] and at the north-west part of the domain [CDD ( $\sim 6$ days)]. Although for the latter, it is worth mentioning that the climatological value of CDD is higher than in the south (around 20-25 days in the north and 5-10 days in the south) and hence the relative sensitivity is lower (15-20\%) in the north than in the south $(\sim 25-35 \%$ over the Great Lakes and in southern and eastern parts of Québec areas).

For JJA, the areas of high sensitivity are located south of the Great Lakes [Precip $(\sim 2 \mathrm{~mm})$, P95 $(\sim 12 \mathrm{~mm})$, CDD 
JJA

$R_{\text {DS_RCM }}$ - Precip

(a)

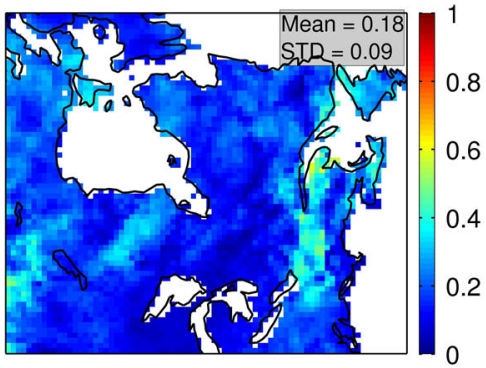

(b)

$\mathrm{R}_{\mathrm{C} \text { AOGCM }}$ - Precip

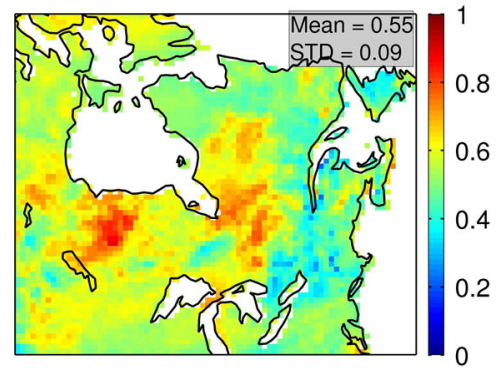

$R_{D S \_R C M}-\operatorname{PrCp} 1$

(d)

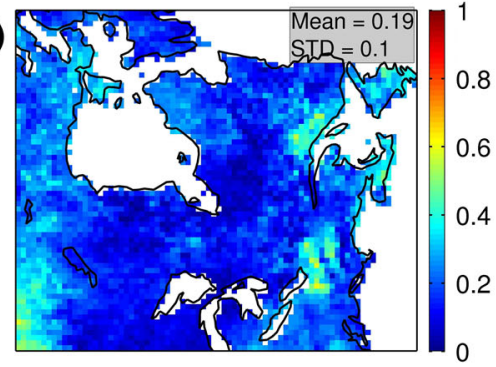

$\mathrm{R}_{\mathrm{DS} \_ \text {RCM }}-\mathrm{CDD}$

(g)

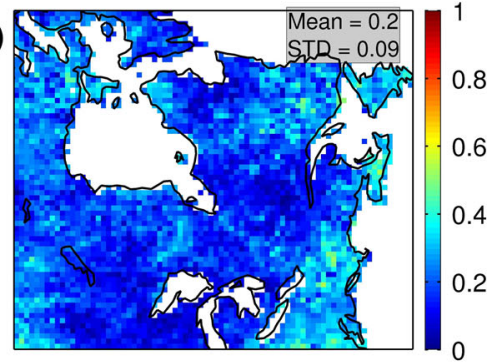

$R_{\text {DS_RCM }}$ - P95

(j)

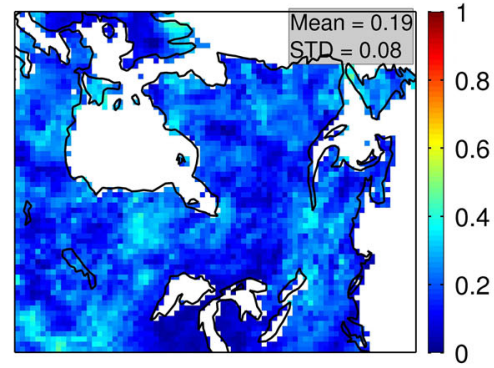

(e)

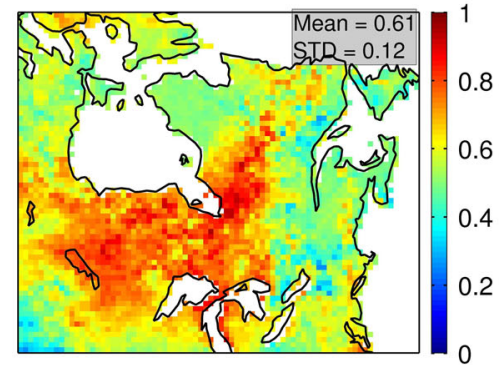

$\mathrm{R}_{\text {C_AOGCM }}$ - CDD

(h)
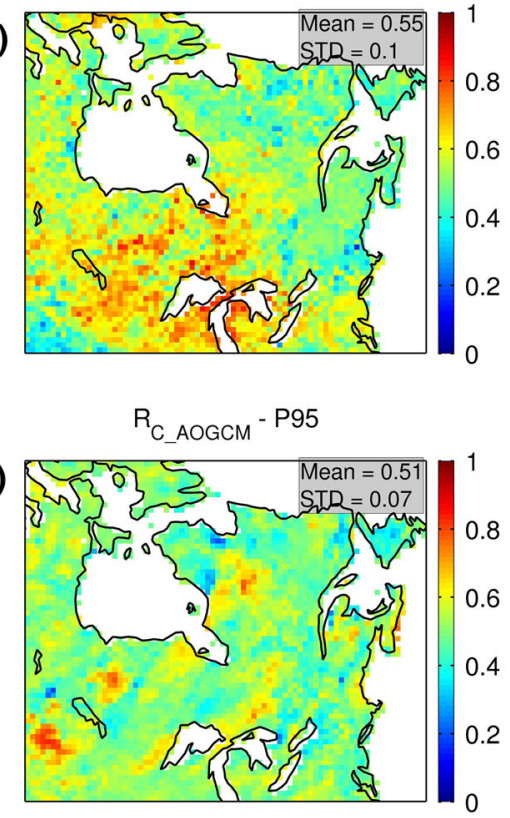

$\mathrm{R}_{\mathrm{M} \text { AOGCM }}$ - Precip

(c)

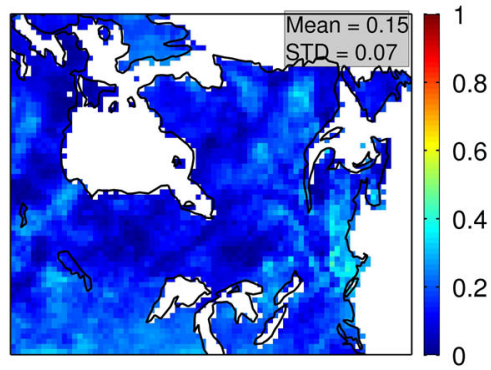

$R_{M \_A O G C M}$ - Prcp1

(f)

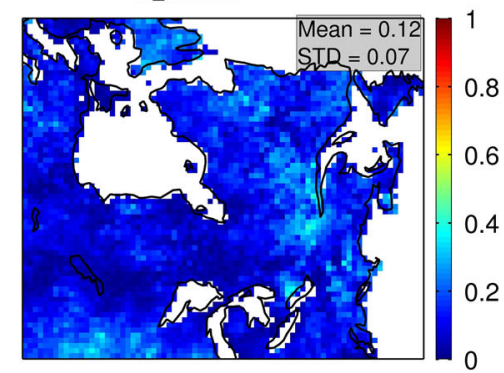

(i)

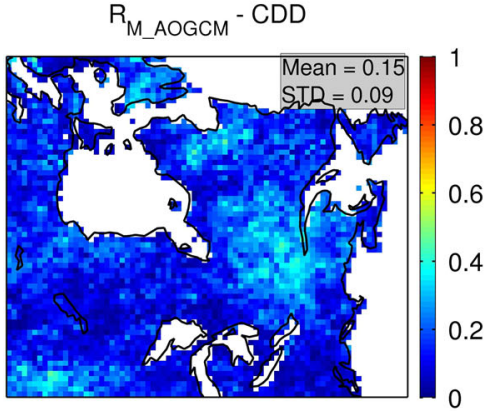

(I)

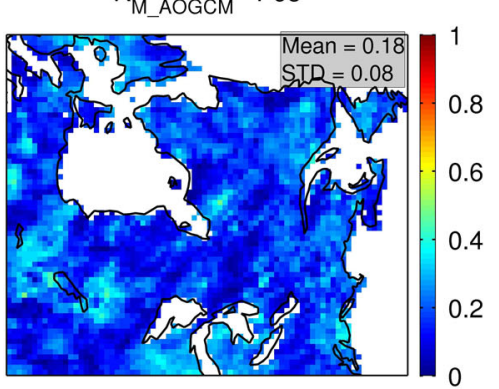

Fig. 8 Summer (JJA) relative contribution to the total uncertainty (R) of DS_RCM (left panels), C_AOGCM (middle panels) and M_AOGCM (right panels) for Precip (a-c), Prcp1 (d-f), CDD (g-i) and P95 (j-l)

( 2.5 days) and Prcp1 $(\sim 5 \%)]$, Québec's province northern area $[\operatorname{Prcp} 1(\sim 5 \%)$ and CDD $(\sim 2.5$ days $)]$ and in the north of the Hudson Bay [Prcp1 $(\sim 4 \%)$ and CDD $(\sim 4$ days $)]$.

3.2.1.3 Sensitivity of EAMS to driving member The right panels of Figs. 4 and 5 show the EAMS due to the modification of the driving member (M_AOGCM) for DJF and JJA, respectively. With respect to previous experiments, a lower number of grid points show a statistically significant value, in both seasons. This means that even though M_AOGCM create high variability in winter, all 4 pairs of experiments nevertheless converge towards similar climatological values whatever the precipitation indices. 
Similar to results from DS_RCM and C_AOGCM experiments, a distinctive spatial pattern occurs for the DJF P95 index over the Appalachian Mountains (Fig. 4). Over the same area, JJA CDD shows also a significant pattern ( $\sim 2$ days).

\subsection{2 $R$ spatial patterns}

This section shows the relative contribution of each source of uncertainty to the total uncertainty (see Sect. 2.3.2).

\subsubsection{Sensitivity of $R$ to domain size The left panels of} Figs. 7 and 8 show the relative contribution of DS_RCM to the total uncertainty within our ensemble for DJF and JJA, respectively. In winter, the main spatial sensitivity area is located along the Atlantic Coast and the Appalachian Mountains, along the land-sea contrast where the main storm track is located. For heavy rainfall (P95), DS_RCM can account for more than $60 \%$ of the total uncertainty (or variability), over the Appalachians Mountains, in the southeast part of the common region. For JJA, the main sensitive area is located south of the St-Lawrence Valley (for Precip and Prcp1), which represents 45-60\% of the total uncertainty over this sub-area. There is also a strong dependence to DS_RCM for Prcp1 over Maritimes areas around the Gulf of St-Lawrence ( $\sim 50 \%$ of the total uncertainty).

\subsubsection{Sensitivity of $R$ to driving data (AOGCMs and/or} ERA40 reanalyses) The middle panels of Figs. 7 and 8 show the relative contribution of C_AOGCM to the total uncertainty within our ensemble for DJF and JJA, respectively. We clearly see that the modification of the AOGCM is the largest contributor to the variance. For DJF, the highest sensitive features are located over the Appalachian mountains and along the east coast [for Precip, Prcp1 and CDD C_AOGCM can account for more than $70 \%$ of the total uncertainty], and in the west of the Hudson Bay [for Precip, Prcp1, CDD and P95 C_AOGCM can account for around $70-80 \%$ of the total uncertainty]. For JJA, these features are located south of the Hudson Bay, where C_AOGCM can account for more than $80-90 \%$ of the total uncertainty for Precip, Prcp1 and CDD. For P95, there are smaller but numerous areas in the lee of water masses as high as $80 \%$ of the total uncertainty.

3.2.2.3 Sensitivity of $R$ to driving member The right panels of Figs. 7 and 8 show the relative contribution of M_AOGCM to the total uncertainty within our ensemble for DJF and JJA, respectively. For DJF, the spatial patterns of sensitivity are mostly uniform with the highest contributions to the total uncertainty being located north of the Great Lakes [Prcp1 $(\sim 50 \%)$ ], at the center of the province of Québec [Precip $(\sim 45-50 \%)$ and P95 ( $50 \%)$ and south of the Hudson Bay
$[\mathrm{CDD}(\sim 50 \%)]$. For JJA, these patterns are even more uniform between the Great Lakes and the St-Lawrence River [CDD $(\sim 35-40 \%)$ ] and along the Atlantic Coast [Precip ( $30 \%)]$.

\subsubsection{Global means of EAMS and R}

The spatial average of the EAMS and of the ratio (R) for all precipitation variables due to M_RCM, DS_RCM, M_AOGCM and C_AOGCM is shown in Tables 7 and 8, respectively. In these Tables, we include all grid-points, even if the t-test indicated that the null hypothesis (i.e. means are equal) could be rejected. This ensures that we do not include sampling error and we incorporate equal number of grid-points for all experiments.

The main contributor of EAMS is C_AOGCM, followed by DS_RCM, with minor contribution from M_AOGCM and M_RCM for both seasons and all precipitation variables. DS_RCM EAMS is about twice the sensitivity of M_AOGCM. Worth noting, the standard deviation of EAMS is quite high for DS_RCM, especially in summer, highlighting the strong spatial variability of DS_RCM sensitivity, generated by the important heterogeneity of land characteristics in generating summer precipitation. It is also interesting to see that the source of uncertainty does not differ among indices.

As for $\mathrm{R}$, the main contributor of uncertainty in our ensemble is C_AOGCM with quite similar contribution for DJF and JJA and precipitation indices, except for precipitation occurrence for which larger uncertainty is clearly obtained in summer (i.e. with respect to other indices and the winter season). This last corresponds also to the highest spatial standard deviation values than any other precipitation indices and seasons' contributions. This can result from combined effects of both large-scale and mesoscale (i.e. convective) processes in the summer season on the simulated wet days occurrence uncertainty, which tends to be more systematically higher than dry spells (CDD) or intense precipitation (P95). For M_AOGCM, the second source of uncertainty in winter, there is a slightly higher uncertainty in winter than in summer. When we add up both sources of uncertainty and we average Precip and all 3 indices (last row of Table 8), we get a DJF fraction for $\mathrm{R}$ of 0.76 , compared to 0.71 for JJA. The fraction of uncertainty caused by DS_RCM is less important in DJF than in JJA, as found earlier for the Variance Ratio (see Sect. 3.1) and corresponds to the 2nd source of uncertainty in summer. In general, there are quite similar values between indices and seasons in terms of uncertainty contribution within each experiment or each source of uncertainty, except for the occurrence of wet days as noted before for the C_AOGCM experiments in summer. 
Table 7 Spatially averaged EAMS score for DJF and JJA for Precip, Prcp1, CDD and P95

\begin{tabular}{|c|c|c|c|c|c|c|c|c|}
\hline & \multicolumn{8}{|c|}{ 1961-1990 } \\
\hline & \multicolumn{4}{|l|}{ DJF } & \multicolumn{4}{|l|}{ JJA } \\
\hline & M_RCM & DS_RCM & M_AOGCM & C_AOGCM & M_RCM & DS_RCM & M_AOGCM & C_AOGCM \\
\hline $\begin{array}{l}\text { Precipitation } \\
(\mathrm{mm} / \text { day })\end{array}$ & $\begin{array}{l}0.03 \\
(0.04)\end{array}$ & $\begin{array}{l}0.14 \\
(0.09)\end{array}$ & $0.07(0.05)$ & $0.30(0.12)$ & $\begin{array}{l}0.06 \\
(0.04)\end{array}$ & $\begin{array}{l}0.31 \\
(0.3)\end{array}$ & $0.13(0.09)$ & $\begin{array}{l}0.44 \\
(0.4)\end{array}$ \\
\hline $\begin{array}{l}\text { Prcp1 } \\
(\%)\end{array}$ & \begin{tabular}{|l}
0.19 \\
$(0.15)$ \\
\end{tabular} & $\begin{array}{l}0.71 \\
(0.41)\end{array}$ & $0.38(0.25)$ & $2.18(0.72)$ & \begin{tabular}{|l}
0.26 \\
$(0.19)$ \\
\end{tabular} & $\begin{array}{l}0.84 \\
(0.81)\end{array}$ & $0.43(0.33)$ & $1.22(0.96)$ \\
\hline $\begin{array}{l}\text { CDD } \\
\text { (days) }\end{array}$ & $\begin{array}{l}0.32 \\
(0.25)\end{array}$ & $\begin{array}{l}0.76 \\
(0.67)\end{array}$ & $0.58(0.49)$ & $2.50(1.34)$ & $\begin{array}{l}0.22 \\
(0.18)\end{array}$ & $\begin{array}{l}0.38 \\
(0.39)\end{array}$ & $0.29(0.26)$ & $0.59(0.52)$ \\
\hline $\begin{array}{l}\text { P95 } \\
\text { (mm/day) }\end{array}$ & \begin{tabular}{|l}
0.29 \\
$(0.32)$ \\
\end{tabular} & $\begin{array}{l}0.97 \\
(1.08)\end{array}$ & $0.66(0.51)$ & $1.62(0.82)$ & $\begin{array}{l}0.61 \\
(0.47)\end{array}$ & $\begin{array}{l}1.39 \\
(1.34)\end{array}$ & $0.81(0.63)$ & $\begin{array}{l}2.61 \\
(1.9) \\
\end{array}$ \\
\hline
\end{tabular}

Red refers to the most important source of uncertainty, blue to the 2nd most important source of uncertainty, green to the 3rd and yellow to the least important source of uncertainty. Number in parentheses is the spatial standard deviation of the EAMS

Table 8 Spatially averaged R score for DJF and JJA for Precip, Prcp1, CDD and P95

\begin{tabular}{|c|c|c|c|c|c|c|c|c|}
\hline & \multicolumn{8}{|c|}{ 1961-1990 } \\
\hline & \multicolumn{4}{|l|}{ DJF } & \multicolumn{4}{|l|}{ JJA } \\
\hline & M_RCM & DS_RCM & M_AOGCM & C_AOGCM & M_RCM & DS_RCM & M_AOGCM & C_AOGCM \\
\hline Precipitation & $\begin{array}{l}0.10 \\
(0.05)\end{array}$ & $\begin{array}{l}0.14 \\
(0.08)\end{array}$ & $\begin{array}{l}0.21 \\
(0.10)\end{array}$ & $\begin{array}{l}0.55 \\
(0.06)\end{array}$ & $\begin{array}{l}0.12 \\
(0.07)\end{array}$ & $\begin{array}{l}0.18 \\
(0.09)\end{array}$ & $\begin{array}{l}0.15 \\
(0.07)\end{array}$ & $\begin{array}{l}0.55 \\
(0.09)\end{array}$ \\
\hline Prcp1 & \begin{tabular}{|l|}
0.12 \\
$(0.06)$
\end{tabular} & \begin{tabular}{|l|}
0.13 \\
$(0.07)$
\end{tabular} & $\begin{array}{l}0.22 \\
(0.10)\end{array}$ & \begin{tabular}{|l|}
0.53 \\
$(0.07)$
\end{tabular} & \begin{tabular}{|l|}
0.08 \\
$(0.06)$
\end{tabular} & $\begin{array}{l}0.19 \\
(0.10)\end{array}$ & $\begin{array}{l}0.12 \\
(0.07)\end{array}$ & $\begin{array}{l}0.61 \\
(0.12)\end{array}$ \\
\hline CDD & \begin{tabular}{|l|}
0.1 \\
$(0.07)$
\end{tabular} & \begin{tabular}{|l|}
0.15 \\
$(0.09)$
\end{tabular} & $\begin{array}{l}0.22 \\
(0.10)\end{array}$ & \begin{tabular}{|l|}
0.52 \\
$(0.06)$
\end{tabular} & \begin{tabular}{|l|}
0.1 \\
$(0.08)$
\end{tabular} & $\begin{array}{l}0.2 \\
(0.09)\end{array}$ & $\begin{array}{l}0.15 \\
(0.09)\end{array}$ & $\begin{array}{l}0.55 \\
(0.10)\end{array}$ \\
\hline P95 & \begin{tabular}{|l|}
0.08 \\
$(0.06)$
\end{tabular} & \begin{tabular}{|l|}
0.16 \\
$(0.11)$
\end{tabular} & $\begin{array}{l}0.22 \\
(0.10)\end{array}$ & \begin{tabular}{|l|}
0.55 \\
$(0.08)$
\end{tabular} & \begin{tabular}{|l|}
0.12 \\
$(0.09)$
\end{tabular} & $\begin{array}{l}0.19 \\
(0.08)\end{array}$ & \begin{tabular}{|l|}
0.18 \\
$(0.08)$
\end{tabular} & $\begin{array}{l}0.51 \\
(0.07)\end{array}$ \\
\hline $\begin{array}{l}\text { Mean } \\
\text { for all } \\
\text { indices }\end{array}$ & 0.1 & 0.15 & 0.22 & 0.54 & 0.11 & 0.19 & 0.15 & 0.56 \\
\hline
\end{tabular}

Red refers to the most important source of uncertainty, blue to the 2nd most important source of uncertainty, green to the 3rd and yellow to the least important source of uncertainty. Number in parentheses is the spatial standard deviation of $R$

\section{Discussion}

\subsection{Overview and causes of sensitivity}

\subsubsection{Overview}

Our results show that the modification of the driving model (i.e. choice of AOGCM and/or reanalysis, C_AOGCM) is the main source of uncertainty in all of our analysis criteria and for both seasons, in line with conclusions in Fowler and Ekström (2009). Depending on the season and the analysis criterion, the second highest source of uncertainty in terms of total uncertainty ("R", see Sect. 2.3.2) is the modification of the member for a given model (M_AOGCM) in winter and the modification of the domain size (DS_RCM) in summer. In terms of climatological sensitivity ("EAMS", see Sect. 2.3.2), DS_RCM is the second source of uncertainty in both seasons while M_AOGCM is the third. In other words, M_AOGCM produces higher sensitivity in the interannual variability than DS_RCM while keeping the climatological value more or less intact. The lower source of uncertainty (but still representing about $10 \%$ of the total uncertainty in our ensemble in both seasons) is the internal variability (M_RCM) of the CRCM.

\subsubsection{Modification of driving data (C_AOGCM)}

The effects of driving conditions within the RCM domain have emerged as the major source of uncertainties for the simulated precipitation (occurrence, duration and intensity) for both seasons, representing between $52 \%$ and $61 \%$ of 
the total uncertainty (see Table 8). The LBCs have important effects because they strongly vary among different AOGCMs (cf. Randall et al. (2007) in terms of largescale circulation, SSTs (Sea Surface Temperatures) spatial distribution, sea-ice cover, as well as humidity advection into the CRCM. Those involve the largest changes in the imposed variables (winds, air temperatures, pressure and water vapour) at the LBC, which in turn modify the simulated fields within the RCM domain whatever the size of the domain. It is worth noting, for example, that most of the AOGCMs have air temperature cold biases $\left(\sim 1-2{ }^{\circ} \mathrm{C}\right)$ in the Arctic region (Chapman and Walsh 2007), which, in turn, influence the CRCM simulations not only through the LBC but also through the spectral nudging technique used in the simulations.

The importance of the C_AOGCM uncertainty source confirms results found in previous studies for mean simulated precipitation over North America (de Elía and Côté 2010), United Kingdom (Rowell 2006) and over other areas in the mid-latitudes (Rowell 2011) and extend it to seasonal precipitation extremes.

\subsubsection{Modification of driving member (M_AOGCM)}

Due to an identical formulation, inter-member variability (i.e. between 2 members of the same AOGCM) arises from the chaotic nature of the climate system. As such, M_AOGCM simulations converge towards similar 30-year climatology (cf. right panels of Figs. 4 and 5), with the exception of winter heavy rainfall (Fig. 4) over the Appalachians Mountains, highlighting the importance of fine-scale forcing that amplify the slight differences in the atmospheric circulation between the two members. M_AOGCM show some important sensitivity at the interannual timescales from the (model) internal atmospheric variability (Deser et al. 2012), as shown in Fig. 3.

\subsubsection{Modification of domain size (DS_RCM)}

Our results show that the smaller CRCM domain produces higher climatological seasonal values with higher interannual variability for precipitation indices for both winter and summer than the larger domain. This higher temporal variance is in line with results from Leduc and Laprise (2009) that showed that the transient-eddy variance of precipitation of their smaller domain was higher than their bigger domain. However, the simulations used in Leduc and Laprise (2009) were not spectrally nudged. Using a different CRCM version, Music et al. (2009) also found that the AMNO domain was producing a drier climate (annual mean precipitation), compared to the smaller QC domain and that the choice of simulation domain had an important effect on the hydrological regime at the watershed scale, more so than a change in the LBCs. A closer look at the seasonal behaviour shows that the DJF simulations climatology (not shown) produces lower precipitation values from the use of ECHAM5 (both members) and ERA40 with AMNO, while precipitation values are slightly higher with AMNO when CGCM3 (both members) is used. For JJA, all drivers produce higher precipitation values with the smaller QC grid. Finally, we note that our simulations uses spectral nudging to keep the large scales of the RCM close to the driving data. This has the effect of reducing DS_RCM values since the RCM has less freedom in generating his own large-scales features. In that respect, our results are the lower bounds of domain size sensitivity.

The sensitivity from the domain size is also inherently associated with the location of the considered domain of comparison. In our case, the smaller domain (i.e. the common area of interest) is located in the eastern part of the larger domain. This, combined with the dominant eastward propagation of weather systems, has some substantial effects arising from the upstream modeling differences between the low-resolution driver (i.e. CGCM3, ECHAM5 or ERA40) and the regional scale processes developed over western Canada that both feed the common eastern region of analysis. Hence, the higher resolution of the orography (ex. Rocky Mountains) and land-sea contrasts (i.e. Mexico Gulf coast, West Coast), the higher surface conditions heterogeneity and land-surface processes and/or stronger vertical motions (over topography and from mesoscale system developments) tends to produce higher precipitation on these upstream regions (Kendon et al. 2012; Lee et al. 2006). This can induce a depletion of the humidity transported (which comes mainly from the Gulf of Mexico and from the Atlantic, see Brubaker et al. 2001) into the common downstream region, resulting in lower precipitation values and different climatology (not shown), as well as a lower interannual variability (Fig. 3) in the larger domain compared to the smaller domain. This highlights the dependence of largeand regional-scale processes and interactions to the RCM domain and its location, as demonstrated by the relative importance of the domain size sensitivity within our ensemble, around $15 \%$ in DJF and $19 \%$ in JJA, on the total uncertainty in the simulated precipitation indices. Thus, a prior identification of processes that are of particular importance in a study is needed before any objective decision on the choice of the domain size and the location can be made.

Another component of the domain-size sensitivity is from the inherent size difference of both domains and the space needed for the small scales to be fully developed. The use of the spectral nudging in all of the simulations means that the large scales inside both domains broadly follow the large scales from the drivers. Hence, some of the 
differences between AMNO and QC grids should arise from differences in small scales generated by the two domain sizes. It has been shown that a small domain might prevent to adequate development of these small scales (through a sufficient spatial spin-up) that play an important role for atmospheric fields that are rich in small-scale features such as humidity, vorticity and precipitation (Leduc et al. 2011). As shown by Leduc et al. (2011), through a Big-Brother setup (Leduc and Laprise 2009; Denis et al. 2002), even a domain as large as $140 \times 140$ grid points (compared to our domain that has $67 \times 91$ grid points) will produce lower intensity of small scales in both seasons in the upper troposphere. In the lower troposphere $(>950 \mathrm{hPa}$ ) and for our domain size, the underestimation of the amplitude of small scales is rather low but non-negligible ( $\sim 10 \%$ for relative vorticity, Laprise et al. 2008) and increases rapidly as we move up in altitude. To what extent this small underestimation in the lower atmosphere affects the uncertainty of precipitation and extremes of precipitation is hard to quantify, but differences in small scales between the two domains might play an important role in our results. We could argue that precipitation and especially extremes of precipitation (i.e. P95) are significantly affected by small scale processes, especially in summer where convective processes (which may be affected by other mesoscale processes like differences in low-level jets) and land characteristics play an important role in triggering precipitation. Our results show that the temporal variance of Precip and P95 is higher in both seasons when using the smaller domain. This indicates that either the (assumed) lower amplitude of small scales does not preclude the development of precipitation (and heavy rainfall) or that the drier AMNO simulations are unable to produce a higher magnitude of heavy rainfall downstream of the domain, over the common region, due to the humidity depletion explained earlier.

\subsection{Winter versus summer evaluation}

One possible cause behind winter C_AOGCM sensitivity is linked to the internal atmospheric circulation variability (which is also a key factor behind M_AOGCM sensitivity, the second most important source of total uncertainty in winter). A substantial portion of the atmospheric variability over the eastern part of North America can be linked to teleconnection patterns like, among others, the North Atlantic Oscillation (NAO) index (Hurrell et al. 2003), the Baffin Island-West Atlantic (BWA) index (Shabbar et al. 1997), the Northern Annular Mode (NAM, Thompson et al. 2003) or the El Niño-Southern Oscillation (ENSO) (cf. Trenberth et al. 2007). These teleconnection patterns regulate the transport and distribution of atmospheric moisture and influence the spatial patterns of precipitation (Hurrell et al. 2003) and hence, modulate the storm track, especially in winter when the atmospheric circulation is stronger (i.e. than in summer). Moreover, these teleconnection patterns have considerable inter-model differences and biases (temporal variability and spatial patterns) in AOGCMs (Stoner et al. 2009), in spite of the fact that most recent AOGCMs have better resolved their patterns, especially CGCM3 versus the old CGCM2 (e.g. Harding et al. 2011). The reproduction of these teleconnection patterns will also vary between members of the same AOGCM due to the intrinsic atmospheric dynamics (Deser et al. 2012), which would explain the importance of M_AOGCM in the interannual variability of Precip and P95 (Fig. 3) and the non-negligible role of M_AOGCM in winter total uncertainty (Fig. 7, right panels).

The summer season is characterized by a higher importance of fine scale physical processes that play a key role in the formation of local precipitation, like the strong spatial heterogeneity of summer land characteristics (spatial variability of ground temperatures, evapotranspiration and/or soil moisture content), the stronger insolation over both the land and the oceans, the stronger soil moistureprecipitation feedback or convection process than in winter. Hence, uncertainty in modelling the land-surface processes (Seneviratne et al. 2002; Roy et al. 2012) and landsea warming contrast (Rowell 2009) are possible important factors for the simulation of the summer precipitation, while large-scale circulation modifications are less important in summer due to the weaker atmospheric circulation, but is still non-negligible (Hurrell et al. 2003). This weaker atmospheric circulation allows a higher influence of landsurface processes on a given air parcel or environment (i.e. greater time-residency). Hence, the higher upstream resolution of the AMNO grid (compared to the low resolution drivers) has a significant influence in DS_RCM experiments, as shown in the relative importance of DS_RCM in summer compared to winter (left panels of Figs. 5, 8). However, the DS_RCM EAMS patterns from Fig. 5 are mostly located at the south border, where the coupling between the CRCM and the AOGCM and/or re-analysis takes place and the strong spatial physiographic heterogeneity (i.e. through the presence of Great Lakes and Appalachians Mountains) combines to create a strong sensitivity signal (see the work over Europe in Maraun 2012).

Land-sea contrasts variability between experiments will be mostly modulated by a modification of the oceanic formulation, as well as the parameterization of fluxes between the ocean and atmosphere. This would explain why C_AOGCM has such an importance in summer. In addition to pressure field variability, this inter-model landsea contrasts variability will generate different evaporation rate over the oceans and, in turn, create some variability in the advection of water vapour at the CRCM boundaries. It 
Fig. 9 Ratios of R_EMS of P95 over R_EMS of Precip
Ratio of relative sensitivity of P95 to Precip for TOT-DJF-1961-1990

(a)

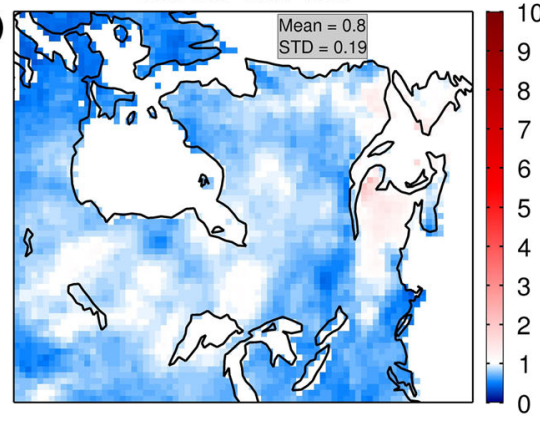

Ratio of relative sensitivity of P95 to Precip for TOT-JJA-1961-1990

(b)

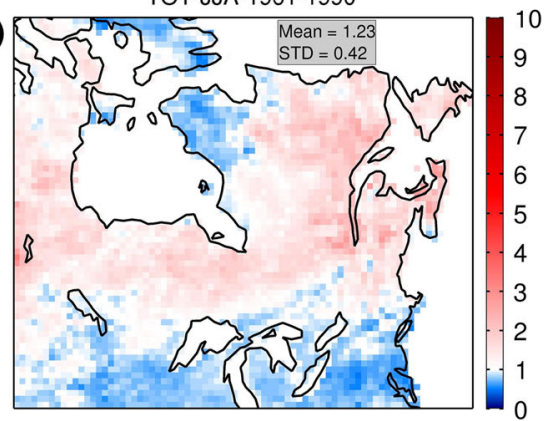

is worth mentioning that AOGCMs tends to have cold SST bias over the Hudson Bay and the Gulf of Mexico and a warm SST bias alongside the northeastern Atlantic Coast (Randall et al. 2007). Theses biases have an important influence over the land regions by influencing the evaporation rates and modulating the storm tracks over the continental region. In comparison, the inter-member (i.e. M_AOGCM) summer SSTs differences should be far less important and hence will create less variability in land-sea contrasts.

\subsection{Heavy rainfall and mean precipitation}

One question of specific interest is to see whether or not heavy rainfall is more uncertain than mean precipitation. As suggested previously, convective processes in summer play a larger role in heavy rainfall than in mean precipitation. As stated by Hohenegger et al. (2008) and Lynn et al. (2009), convective parameterisation is an important potential source of precipitation uncertainty. Figure 9 shows the average of the 24 sensitivity experiments (defined in Table 4) ratio of the R_EMS (see Sect. 2.3.2) of P95 on the R_EMS of Precip, to analyze if the sensitivity of extreme values is higher than mean precipitation values. It is interesting to see that for DJF, the relative sensitivity of Precip is higher than for P95 over most of the domain $(-20 \%$ on the average), but with the exception of the New-Brunswick, Gaspé Peninsula and NewfoundlandLabrador regions, which coincide with the highest density of extratropical storms over the eastern coast in winter. For JJA the behaviour is inversed, with the central part of the domain showing that $\mathrm{P} 95$ relative sensitivity is higher than for Precip ( $+23 \%$ on the average).

The consideration of the ratio of the standard deviation of the 30-year interannual variability of $\mathrm{P} 95$ over Precip gives us an indication on the estimation error of both quantities. Figure 10 shows the ratio of the standard deviation of the interannual variability of P90 (i.e. the 90th percentile of daily precipitation) and P95 over Precip for a given simulation ("aet", see Table 2, other simulations, not shown, suggest similar values). In this case for P95, when we consider the interannual variability distributions, we have a ratio that varies from 2 to 8 for both DJF and JJA, with a mean ratio of 5.52 (DJF) and 5.29 (JJA). For P90, the ratios are much lower with 3.5 for DJF and 3.24 for JJA. Other seasons (not shown) show similar patterns. Hence, from an interannual variability point of view, the uncertainty seems to be much more important for heavy rainfall than for mean seasonal precipitation in both seasons, with increasing ratios for higher percentiles. The higher standard deviation of higher percentiles can be caused by numerous factors: non-linearity processes involved in heavy rainfall, the non-linear effect of the natural variability on the daily precipitation distribution or the standard error differences between mean values and high quantile.

\section{Conclusions}

In this study, an assessment of four sources of uncertainty in the CRCM simulations (Internal Variability-M_RCM; Domain Size-DS_RCM; Member choice of a given AOGCM-M_AOGCM; and choice of an AOGCMC_AOGCM) has been done over winter (December-February, DJF) and summer (June-August, JJA) seasons for mean and extreme indices of precipitation (i.e. wet days, dry sequences, and 95th daily precipitation). We use 16 historical simulations (1961-1990) using a recent version (4.2.3) of the CRCM. The assessment of uncertainty is made by analyzing the temporal variance ratio (VR), the 30-year climatology spatial correlation (SC), the EAMS and variance decomposition $\left(\mathrm{R}_{\mathrm{s}}\right)$ of each source of uncertainty.

Results show that over a common region located in eastern Canada, the main sources of uncertainties are issued from the boundary conditions (i.e. C_AOGCM), followed by the domain size (i.e. DS_RCM) and the choice of AOGCM members (i.e. M_AOGCM). The internal variability (M_RCM) is found to have minor effects on these simulated uncertainties in general. In terms of total 
Fig. 10 Ratio of the standard deviation of the interannual variability of heavy rainfall [90th (left panel) and 95th (right panel) percentile] over the standard deviation of the interannual variability of mean seasonal precipitation (i.e. Precip) $\sigma_{90} / \sigma_{\mu}$ ratio for DJF

(a)

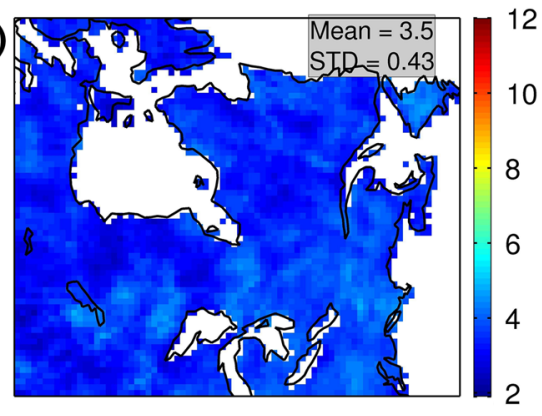

$\sigma_{90} / \sigma_{\mu}$ ratio for JJA

(c)

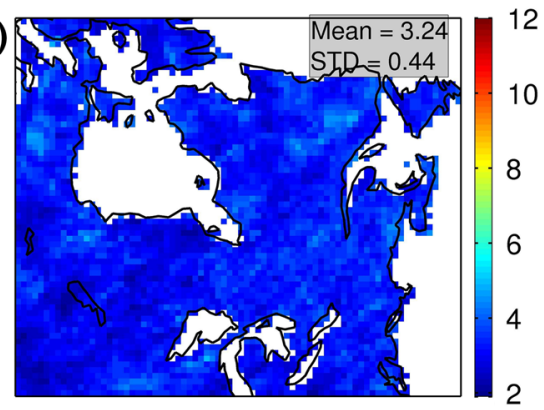

$\sigma_{95} / \sigma_{\mu}$ ratio for DJF

(b)

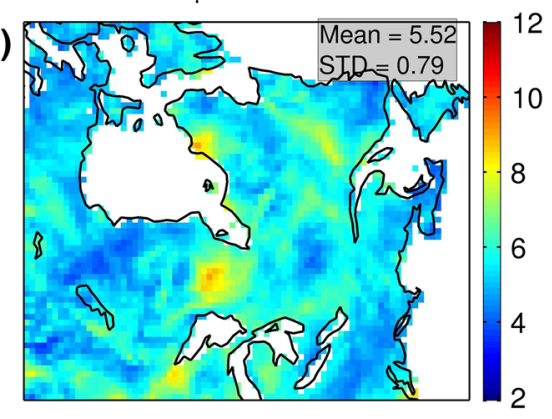

$\sigma_{95} / \sigma_{\mu}$ ratio for JJA

(d)

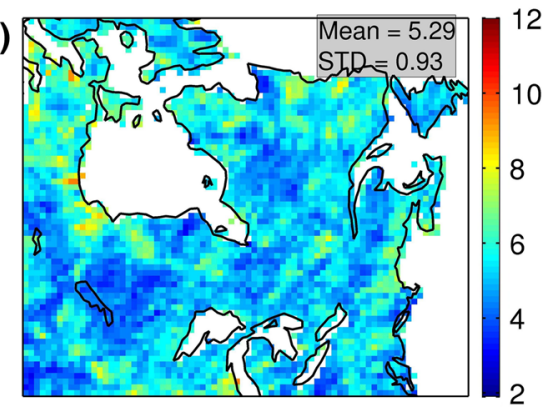

uncertainty, the most important sources of uncertainty in winter over the whole region are, in decreasing order: C_AOGCM (54\%), M_AOGCM (22\%), DS_RCM $(15 \%)$ and M_RCM (10\%). In summer, those are: C_AOGCM (56\%), DS_RCM (19\%), M_AOGCM $(15 \%)$ and M_RCM (11\%). For specific regions (i.e. StLawrence Valley and the south of Great Lakes area), DS_RCM can even surpass the uncertainty due to the choice of AOGCM. This is consistent with the larger role of local physics in summer precipitation in the context of weaker atmospheric flow from the lateral boundary conditions with respect to winter. In this last season, around $75 \%$ of the total uncertainty, for Precip and all extreme indices come from the lateral boundary conditions, i.e. the large-scale atmospheric circulation influences. The smaller domain produces higher climatological precipitation amount as well as the climatological value of heavy precipitation and wet-days frequency, and shorter seasonal dry sequences. Moreover, the estimated sensitivity arising from a modification of the domain size is probably a lower bound, since our simulations used spectral nudging of large-scale winds, limiting the RCM in the development of his own climate. The smaller domain also produces higher variance of Precip, Prcp1 and P95. Some regions where land-sea contrasts or orographic features are important show a higher systematic sensitivity for the four sources of uncertainties: the maritime coast, the Appalachians Mountains, the Great Lakes and the St-Lawrence Valley.

The main outcomes from this study are:
- The quantification of the uncertainty is dependent to the sample size used. As the uncertainty of heavy precipitation (i.e. 95th percentile) is higher than the uncertainty of mean seasonal precipitation, this further highlights the importance of using the largest ensemble as possible, especially when extremes are concerned. As such, ideal ensemble size could be substantially different for mean precipitation values than when daily precipitation extremes are concerned.

- As the driven conditions and their effects on the regional-scale simulated precipitation values depend or combine with the domain size and vary at the spatial and temporal scales, these interdependency needs to be taken into account in any uncertainty analysis method, especially to account for the dependency of the climate models of biases or systematic errors from various combinations of large-scale and regional-scale factors. In other words, two models are not independent because they produce different results, but rather because they reach them using different paths (Pennell and Reichler 2010; Knutti et al. 2013). This is of the utmost importance for climate change projections and the analysis of the full range of uncertainties and of climate change signals.

- Caution should be applied when choosing the domain size and location for a simulation, while the other sources of uncertainty from the LBCs are unavoidable. Also, the distance between the lateral boundary 
location and the study area should be accounted for to minimize the effect of coupling errors over the area of interest.

- The higher uncertainty in the simulation of heavy precipitation than for mean seasonal precipitation might be primarily caused by the quantile estimation alone, and not only related to the underlying uncertainty in the physical parameterizations of the climate models.

Upcoming works include the analysis over spring and autumn seasons. Preliminary results show that the sensitivity suggests a strong seasonal behaviour, as expected from the seasonal variations of physical and dynamical processes in mid-latitude climates. The ability to reproduce the historical climate is not an indicator that it will perform in a similar way in the future. As noted in the recent study of Maraun (2012) over Europe, non-stationarity of RCMs biases still exists. Hence, sensitivity of extremes of precipitation could also be a function of time. A similar analysis is under way for the period of 2041-2070, with the same model configuration. Moreover, we will be able to see if the climate change signal of extremes of precipitation is also affected by these modifications to model configurations. A validation of both domain sizes and various CRCM configurations against an observation database is underway to assess potential biases with respect to characteristics of observed extreme events. Finally, a similar work is under way to assess the uncertainty of temperature extreme indices from the same sources of sensitivity.

Acknowledgments The authors would like to thank the Ouranos Climate Simulation team for generating and supplying output from the numerous CRCM simulations. We thank the two anonymous reviewers for their constructive comments to improve the final version of this manuscript. We thank the financial supports from the National Sciences and Engineering Research Council (NSERC) of Canada, Environment Canada and Centre ESCER (http://www.escer. uqam.ca/). Other financial supports from the IRIACC (The International Research Initiative on Adaptation to Climate Change)-FACE project (see http://face.ete.inrs.ca/) is also acknowledged. IRIACC is managed by the IDRC (International Development Research Center), co-financed by the IDRC, the Canadian Health Research Institutes, the SSHRC (Social Sciences and Humanities Research Council of Canada) and the NSERC (Natural Sciences and Engineering Research Council of Canada).

Open Access This article is distributed under the terms of the Creative Commons Attribution License which permits any use, distribution, and reproduction in any medium, provided the original author(s) and the source are credited.

\section{References}

Alexandru A, de Elia R, Laprise R, Separovic L, Biner S (2009) Sensitivity study of regional climate model simulations to largescale nudging parameters. Mon Weather Rev 137(5):1666-1686. doi:10.1175/2008MWR2620.1
Bechtold P, Bazile E, Guichard F, Mascart P, Richard E (2001) A mass-flux convection scheme for regional and global models. Q J R Meteorol Soc 127(573):869-886. doi:10.1002/qj.49712757309

Beniston M, Stephenson D, Christensen O, Ferro C, Frei C, Goyette S, Halsnaes K, Holt T, Jylhä K, Koffi B, Palutikof J, Schöll R, Semmler T, Woth K (2007) Future extreme events in European climate: an exploration of regional climate model projections. Clim Change 81:71-95. doi:10.1007/s10584-006-9226-Z

Biner S, Caya D, Laprise R, Spacek L (2000) Nesting of RCMs by imposing large scales. Atmosp Ocean Model 987. WMO/TD

Brochu R, Laprise R (2007) Surface water and energy budgets over the Mississippi and Columbia river basins as simulated by two generations of the Canadian Regional Climate Model. Atmos Océan 45(1):19-35

Brubaker KL, Dirmeyer PA, Sudradjat A, Levy BS, Bernal F (2001) A 36-yr climatological description of the evaporative sources of warm-season precipitation in the Mississippi River basin. J Hydrometeorol 2(6):537-557. doi:10.1175/15257541(2001)002<0537:AYCDOT>2.0.CO;2

Caya D, Laprise R (1999) A semi-implicit semi-Lagrangian regional climate model: the Canadian RCM. Mon Weather Rev 127:341-362

Chapman WL, Walsh JE (2007) Simulations of arctic temperature and pressure by global coupled models. J Climate 20:609-632. http:// dx.doi.org/10.1175/JCLI4026.1

Christensen J, Christensen O (2007) A summary of the PRUDENCE model projections of changes in European climate by the end of this century. Clim Change 81:7-30. doi:10.1007/s10584-006-9210-7

Colin J, Déqué M, Radu R, Somot S (2010) Sensitivity study of heavy precipitation in Limited Area Model climate simulations: influence of the size of the domain and the use of the spectral nudging technique. Tellus A 62A:591-604

de Elía R, Côté H (2010) Climate and climate change sensitivity to model configuration in the Canadian RCM over North America. Meteorol Z 19:325-339

de Elía R, Caya D, Côté H, Frigon A, Biner S, Giguère M, Paquin D, Harvey R, Plummer D (2008) Evaluation of uncertainties in the CRCM-simulated North American climate. Clim Dyn 30(2):113-132. doi:10.1007/s00382-007-0288-z

Denis BD, Laprise RL, Caya DC, Côté JC (2002) Downscaling ability of one-way nested regional climate models: the Big-Brother Experiment. Clim Dyn 18(8):627-646. doi:10.1007/s00382-0010201-0

Déqué M, Rowell D, Lüthi D, Giorgi F, Christensen J, Rockel B, Jacob D, Kjellström E, de Castro M, van den Hurk B (2007) An intercomparison of regional climate simulations for Europe: assessing uncertainties in model projections. Clim Change 81:53-70. doi:10.1007/s10584-006-9228-x

Deser C, Phillips A, Bourdette V, Teng H (2012) Uncertainty in climate change projections: the role of internal variability. Clim Dyn 38(3-4):527-546. doi:10.1007/s00382-010-0977-x

Fiorino M (1997) AMIP II sea surface temperature and sea ice concentration observations. http://www-pcmdi.llnl.gov/projects/ amip/AMIP2EXPDSN/BCS_OBS/amip2_bcs.htm. Accessed 29 March 2012

Fowler HJ, Ekström M (2009) Multi-model ensemble estimates of climate change impacts on UK seasonal precipitation extremes. Int J Climatol 29(3):385-416. doi:10.1002/joc.1827

Frigon A, Music B, Slivitzky M (2010) Sensitivity of runoff and projected changes in runoff over Quebec to the update interval of lateral boundary conditions in the Canadian RCM. Meteorol Z 19(3):225-236

Goyette S, McFarlane N, Flato GM (2000) Application of the Canadian Regional Climate Model to the Laurentian Great Lakes region: implementation of a lake model. Atmos Ocean 38(3):481-503 
Harding AE, Gachon P, Nguyen V-T-V (2011) Replication of atmospheric oscillations, and their patterns, in predictors derived from Atmosphere-Ocean Global Climate Model output. Int J Climatol 31(12):1841-1847. doi:10.1002/joc.2191

Hennessy K, Suppiah R, Page CM (1999) Australian rainfall changes, 1910-1995. Aust Meteorol Mag 48:1-13

Hewitt CD (2004) Ensembles-based predictions of climate changes and their impacts. Eos Trans AGU 85(52). doi:10.1029/ 2004eo520005

Hohenegger C, Brockhaus P, Schar C (2008) Towards climate simulations at cloud-resolving scales. Meteorol $\mathrm{Z}$ 17(4):383-394. doi:10.1127/0941-2948/2008/0303

Hurrell JW, Kushnir Y, Otterson G, Visbeck M (2003) An overview of the North Atlantic Oscillation. The North Atlantic Oscillation: climatic significance and environmental impact, vol 134. American Geophysical Union, Washington, DC

Kalnay E, Kanamitsu M, Kistler R, Collins W, Deaven D, Gandin L, Iredell $\mathrm{M}$, Saha S, White $\mathrm{G}$, Woollen J, Zhu Y, Leetmaa A, Reynolds R, Chelliah M, Ebisuzaki W, Higgins W, Janowiak J, Mo KC, Ropelewski C, Wang J, Jenne R, Joseph D (1996) The NCEP/NCAR 40-year reanalysis project. Bull Am Meteorol Soc 77(3):437-471

Katz RW, Brown BG (1992) Extreme events in a changing climate: variability is more important than averages. Clim Change 21(3):289-302. doi:10.1007/bf00139728

Kendon EJ, Rowell DP, Jones RG, Buonomo E (2008) Robustness of future changes in local precipitation extremes. J Clim 21(17):4280-4297. doi:10.1175/2008jcli2082.1

Kendon EJ, Roberts NM, Senior CA, Roberts MJ (2012) Realism of rainfall in a very high resolution regional climate model. J Clim. doi:10.1175/jcli-d-11-00562.1

Kjellström E, Giorgi F (2010) Introduction. Clim Res 44:117-119

Knutti R, Masson D, Gettelman A (2013) Climate model genealogy: generation CMIP5 and how we got there. Geophys Res Lett 40(6):1194-1199. doi:10.1002/grl.50256

Laprise R (2003) Resolved scales and nonlinear interactions in limited-area models. J Atmos Sci 60(5):768-779. doi:10.1175/ 1520-0469(2003)060<0768:RSANII >2.0.CO;2

Laprise R, Caya D, Bergeron G, Giguère M (1997) The formulation of the André Robert MC2 (mesoscale compressible community) model. Atmos Océan 35(sup1): 195

Laprise R, de Elia R, Caya D, Biner S, Lucas-Picher P, Diaconescu E, Leduc M, Alexandru A, Separovic L, Diagnostics CNfRCMa (2008) Challenging some tenets of regional climate modelling. Meteorol Atmos Phys 100:3-22. doi:10.1007/s00703-008-02929

Leduc M, Laprise R (2009) Regional climate model sensitivity to domain size. Clim Dyn 32(6):833

Leduc M, Laprise R, Moretti-Poisson M, Morin J-P (2011) Sensitivity to domain size of mid-latitude summer simulations with a regional climate model. Clim Dyn 37(1):343-356. doi:10.1007/ s00382-011-1008-2

Lee M-I, Schubert SD, Suarez MJ, Held IM, Kumar A, Bell TL, Schemm J-KE, Lau N-C, Ploshay JJ, Kim H-K, Yoo S-H (2006) Sensitivity to horizontal resolution in the AGCM simulations of warm season diurnal cycle of precipitation over the United States and northern Mexico. J Clim 20:1862-1881

Lucas-Picher P, Caya D, de Elía R, Laprise R (2008) Investigation of regional climate models' internal variability with a ten-member ensemble of 10-year simulations over a large domain. Clim Dyn 31(7):927-940. doi:10.1007/s00382-008-0384-8

Lynn BH, Healy R, Druyan LM (2009) Quantifying the sensitivity of simulated climate change to model configuration. Clim Change 92:275-298

Mailhot A, Beauregard I, Talbot G, Caya D, Biner S (2012) Future changes in intense precipitation over Canada assessed from multi-model NARCCAP ensemble simulations. Int J Climatol 32(8):1151-1163. doi:10.1002/joc. 2343

Maraun D (2012) Nonstationarities of regional climate model biases in European seasonal mean temperature and precipitation sums. Geophys Res Lett 39(6):L06706. doi:10.1029/2012g1051210

Maslin M, Austin P (2012) Uncertainty: climate models at their limit? Nature 486(7402):183-184

Mearns LO, Katz RW, Schneider SH (1984) Extreme high-temperature events: changes in their probabilities with changes in mean temperature. J Clim Appl Meteorol 23(12):1601-1613. doi:10. 1175/1520-0450(1984)023<1601:ehteci $>2.0 . c 0 ; 2$

Mearns LO, Giorgi F, McDaniel L, Shields C (2003) Climate scenarios for the southeastern US based on GCM and regional model simulations. Clim Change 60(1):7-35. doi:10.1023/a: 1026033732707

Mearns LO, Gutowski W, Jones R, Leung R, McGinnis S, Nunes A, Qian Y (2009) A regional climate change assessment program for North America. Eos Trans AGU 90(36). doi:10.1029/ 2009eo360002

Murphy JM, Sexton DMH, Jenkins GJ, Boorman PM, Booth BBB, Brown CC, Clark RT, Collins M, Harris GR, Kendon EJ, Betts RA, Brown SJ, Howard TP, Humphrey KA, Mccarthy MP, Mcdonald RE, Stephens A, Wallace C, Warren R, Wilby R, Wood RA (2009) UK climate projections science report: climate change projections. Met Office Hadley Centre, Exeter

Music B, Caya D (2007) Evaluation of the hydrological cycle over the Mississippi River basin as simulated by the Canadian Regional Climate Model (CRCM). J Hydrometeorol 8(5):969-988. doi:10. 1175/JHM627.1

Music B, Frigon A, Slivitzky M, Musy A, Caya D, Roy R (2009) Runoff modelling within the Canadian Regional Climate Model (CRCM): analysis over the Quebec/Labrador watersheds. Paper presented at the new approaches to hydrological prediction in data-sparse regions, Hyderabad, India, September 2009

Pennell C, Reichler T (2010) On the effective number of climate models. J Clim 24(9):2358-2367. doi:10.1175/2010jcli3814.1

Plummer DA, Caya D, Frigon A, Côté H, Giguère M, Paquin D, Biner S, Harvey R, de Elia R (2006) Climate and climate change over North America as simulated by the Canadian RCM. J Clim 19:3112-3132

Randall DA, Wood RA, Bony S, Colman R, Fichefet T, Fyfe J, Kattsov V, Pitman A, Shukla J, Srinivasan J, Stouffer RJ, Sumi A, Taylor KE (2007) Climate models and their evaluation. In: (Italy) EM, (Japan) TM, (Australia) BM (eds) Climate change 2007: the physical science basis. Groupe d'experts intergouvernemental sur l'évolution du climat, New York

Rinke A, Dethloff K (2000) On the sensitivity of a regional Arctic climate model to initial and boundary conditions. Clim Res 14(2):101-113. doi: $10.3354 / \mathrm{cr} 014101$

Roeckner E, Bäuml G, Bonaventura L, Brokopf R, Esch M, Giorgetta M, Hagemann S, Kirchner I, Kornblueh L, Manzini E, Rhodin A, Schlese U, Schulzweida U, Tompkins A (2003) The atmospheric general circulation model ECHAM 5. Part I: model description. Max-Planck-Institute for Meteorology, Hamburg

Rowell DP (2006) A demonstration of the uncertainty in projections of UK climate change resulting from regional model formulation. Clim Change 79:243-257. doi:10.1007/s10584-006-9100-Z

Rowell DP (2009) Projected midlatitude continental summer drying: North America versus Europe. J Clim 22(11):2813-2833. doi:10. $1175 / 2008$ jcli2713.1

Rowell DP (2011) Sources of uncertainty in future changes in local precipitation. Clim Dyn 1-22. doi:10.1007/s00382-011-1210-2

Roy P, Gachon P, Laprise R (2012) Assessment of summer extremes and climate variability over the north-east of North America as simulated by the Canadian Regional Climate Model. Int J Climatol 32(11):1615-1627. doi:10.1002/joc.2382 
Scinocca JF, McFarlane NA (2004) The variability of modeled tropical precipitation. J Atmos Sci 61(16):1993-2015. doi:10. 1175/1520-0469(2004)061<1993:tvomtp >2.0.co;2

Scinocca JF, McFarlane NA, Lazare M, Li J, Plummer D (2008) The CCCma third generation AGCM and its extension into the middle atmosphere. Atmos Chem Phys Discuss 8(2):7883-7930. doi:10.5194/acpd-8-7883-2008

Seneviratne S, Pal J, Eltahir E, Schär C (2002) Summer dryness in a warmer climate: a process study with a regional climate model. Clim Dyn 20(1):69-85. doi:10.1007/s00382-002-0258-4

Shabbar A, Higuchi K, Skinner W, Knox JL (1997) The association between the BWA index and winter surface temperature variability over eastern Canada and west Greenland. Int J Climatol 17(11):1195-1210. doi:10.1002/(sici)1097-0088 (199709) 17:11<1195:aid-joc190>3.0.co;2-u

Sobolowski S, Pavelsky T (2012) Evaluation of present and future North American regional climate change assessment program (NARCCAP) regional climate simulations over the southeast United States. J Geophys Res 117(D1):D01101. doi:10.1029/ $2011 \mathrm{jd} 016430$

Stoner AMK, Hayhoe K, Wuebbles DJ (2009) Assessing general circulation model simulations of atmospheric teleconnection patterns. J Clim 22(16):4348-4372. doi:10.1175/2009jcli2577.1

Thompson DWJ, Lee S, Baldwin MP (2003) Atmospheric processes governing the northern hemisphere annular mode/North Atlantic Oscillation. The North Atlantic Oscillation: climatic significance and environmental impact, vol 134. American Geophysical Union, Washington, DC

Trenberth KE, Jones PD, Ambenje P, Bojariu R, Easterling D, Tank AK, Parker D, Rahimzadeh F, Renwick JA, Rusticucci M, Soden B, Zhai P (2007) Observations: surface and atmospheric climate change. In: (UK) BJH, (USA) TRK, Gambia) BJT (eds) Climate change 2007: the physical science basis. Groupe d'experts intergouvernemental sur l'évolution du climat, New York

Uppala SM, Kållberg PW, Simmons AJ, Andrae U, Bechtold VDC, Fiorino M, Gibson JK, Haseler J, Hernandez A, Kelly GA, Li X, Onogi K, Saarinen S, Sokka N, Allan RP, Andersson E, Arpe K, Balmaseda MA, Beljaars ACM, Berg LVD, Bidlot J, Bormann N, Caires S, Chevallier F, Dethof A, Dragosavac M, Fisher M, Fuentes M, Hagemann S, Hólm E, Hoskins BJ, Isaksen L, Janssen PAEM, Jenne R, McNally AP, Mahfouf JF, Morcrette JJ, Rayner NA, Saunders RW, Simon P, Sterl A, Trenberth KE, Untch A, Vasiljevic D, Viterbo P, Woollen J (2005) The ERA-40 re-analysis. Q J R Meteorol Soc 131(612):2961-3012. doi:10. 1256/qj.04.176

van der Linden P, Mitchell J (2009) ENSEMBLES: climate change and its impacts. Summary of research and results from the ENSEMBLES project. Met Office Hadley Centre, Exeter

Vannitsem S, Chomé F (2005) One-way nested regional climate simulations and domain size. J Clim 18(1):229

Verseghy DL (2000) The Canadian land surface scheme (CLASS): its history and future. Atmos Ocean 38(1):1-13

von Storch H, Langenberg H, Feser F (2000) A spectral nudging technique for dynamical downscaling purposes. Mon Weather Rev 128(10):3664-3673. doi:10.1175/1520-0493(2000)128 $<3664$ :asntfd $>2$.0.co; 2

Wehner MF (2013) Very extreme seasonal precipiation in the NARCCAP ensemble: model performance and projections. Clim Dyn 40:59-80. doi:10.1007/s00382-012-1393-1

Wehner MF, Smith RL, Bala G, Duffy P (2010) The effect of horizontal resolution on simulation of very extreme US precipitation events in a global atmosphere model. Clim Dyn 34(2). doi:10.1007/s00382-009-0656-y 